\title{
Effect of helmet liner systems and impact directions on severity of head injuries sustained in ballistic impacts: a finite element (FE) study
}

Kwong Ming Tse ${ }^{1,2, *}$, Long Bin Tan ${ }^{1}$, Bin Yang ${ }^{3}$, Vincent Beng Chye Tan ${ }^{1}$, Heow Pueh Lee ${ }^{1,4}$

${ }^{1}$ Department of Mechanical Engineering, National University of Singapore

9 Engineering Drive 1, Singapore 117576

${ }^{2}$ Department of Mechanical Engineering, University of Melbourne Parkville Campus, Melbourne, VIC 3010, Australia

${ }^{3}$ College of Automobile and Traffic Engineering, Nanjing Forestry University 159 LongPan Rd, Nanjing, People's Republic of China 210037

${ }^{4}$ National University of Singapore (Suzhou) Research Institute 377 Lin Quan Street, Suzhou Industrial Park, Jiang Su

People's Republic of China 215123

*E-mail: tsekm.research@yahoo.com or kmtse@unimelb.edu.au (Tse, KM)

Phone: +61 383447729

Word Count from Title Page to Figure Legend, including Tables \& References): 8739 Word Count for Main Text: $\quad 5736$

$\begin{array}{ll}\text { Word Count for Abstract: } & 201\end{array}$

$\begin{array}{ll}\text { No. of Figures: } & 11\end{array}$

No. of Tables: $\quad 4$

\section{Abstract}


The current study aims to investigate the effectiveness of two different designs of helmet interior cushion, (Helmet 1: strap-netting; Helmet 2: Oregon Aero foam padding), and the effect of the impact directions on the helmeted head during ballistic impact. Series of ballistic impact simulations (frontal, lateral, rear and top) of a full-metal jacketed bullet were performed on a validated finite element head model equipped with the two helmets, to assess the severity of head injuries sustained in ballistic impacts using both head kinematics and biomechanical metrics. Benchmarking with experimental ventricular and intracranial pressures showed that there is good agreement between the simulations and experiments. In terms of extracranial injuries, top impact had the highest skull stress, still without fracturing the skull. In regard to intracranial injuries, both the lateral and rear impacts generally gave the highest principal strains as well as highest shear strains, which exceed the injury thresholds. Off-cushion impacts were found to be at higher risk of intracranial injuries. The study also showed that the Oregon Aero foam pads helped to reduce impact forces. It also suggested that more padding inserts of smaller size may offer better protection. This provides some insights on future's helmet design against ballistic threats.

Keywords: Head model, brain injury, helmet, interior cushion, bullet

\section{Acronyms}

$\mathrm{ACH}$

CG

CSF

CT

DAI

FE

FEHM

FEM
Advanced Combat Helmet

Centre Of Gravity

Cerebrospinal Fluid

Computed Tomography

Diffuse Axonal Injury

Finite Element

Finite Element Head Model

Finite Element Method 


$\begin{array}{ll}\text { FMJ } & \text { Full-Metal Jacketed } \\ \text { G } & \text { Gravitational Constant } \\ \text { HIC } & \text { Head Injury Criterion } \\ \text { ICP } & \text { Intracranial Pressure } \\ \text { MRI } & \text { Magnetic Resonance Imaging } \\ \text { NIJ } & \text { National Institute Of Justice } \\ \text { OA } & \text { Oregon Aero } \\ \text { TBI } & \text { Traumatic Brain Injury }\end{array}$

\section{Introduction}

Given the recent rise in civil and international conflicts, the number of people suffering from ballistic head injuries, is set to increase. According to Mathers et al. [31], ballistic head injuries account for approximately a quarter of the violent deaths occurring annually worldwide. Since these war-related ballistic injuries (from weapons and resultant debris fragments) lead to high mortality rate [8], it is particularly important to ensure that personal protective equipment, especially the combat helmets, are capable and effective in providing protection from ballistic impact. Despite the fact that modern combat helmets can prevent bullets of handguns and even some rifles from penetrating them, traumatic injuries to both the skull and brain can still occur due to the excessive mechanical responses of the helmet and the head. Head injuries can also occur when the bullet has sufficient energy to cause the interior helmet shell to come in contact with the underlying tissue and this is known as "rear effect" [9].

Earlier research in all domains of head protection could be traced back to the 60 s when experiments, as reported in $[5,39,11,43]$ had been performed extensively to investigate on the required head protection in an event of traumatic head injury. However, these tests not only raised ethical issues, but also raised many technical concerns such as inflexibility, biased experimental data due to scarce subjects and non-standardized test procedures. Finite element 
(FE) simulations, which serve as cost-effective alternative to these experimental tests, were then used to understand the mechanism of head injury during impact and how the use of helmets attenuates injuries. Since 1970s, tremendous efforts had been spent on research of head protective helmets using finite element method (FEM) $[16,22,23,55,54,7,1,51,28,60]$. The first few analytical studies by Khalil [22] as well as Goldsmith and Khalil [16] used a simplified axisymmetric elastic head-helmet FE model to investigate the dynamic response of head-helmet in a localized short-duration impact. It was followed by Khalil et al. [23]'s low-velocity ballistic impact study using a simplified axisymmetric elastic head-helmet FE model, which was validated with corresponding experiments. Van Hoof et al. [55,54] performed both experimental and numerical studies on the response of the woven composite helmet materials to ballistic impact, and found that the helmet interior exhibited large deformation which could exceed the gap between inner helmet shell and head [54]. Baumgartner and Willinger [7] simulated highspeed ballistic impact on aluminum military helmet with their FE head model which consisted of basic anatomical components. Their study demonstrated that no traumatic brain injury (TBI) was predicted even in the event of skull fracture. Aare and Kleiven [1] studied the effects of helmet shell stiffness and impact angles' direction on the load levels in human head during a ballistic impact, using a more detailed FE model of human head. They concluded that the helmet shell deflections should not exceed the initial gap between the helmet shell and the head in order to prevent the rear effect as well as the oblique impact of 45 degrees gave highest intracranial strains among all the other impact directions. At the same time, Kleiven [25] also compared a regular strap-netting system with a helmet liner for ballistic helmets. Tham et al. [51] conducted ballistic tests to determine the response of the $\mathrm{KEVLAR}^{\circledR}$ helmet, which was then used as a benchmark for comparison against FE simulation results. It was found that the KEVLAR ${ }^{\circledR}$ 
helmet was capable of deflecting the full-metal jacketed (FMJ) bullet travelling at $358 \mathrm{~m} \cdot \mathrm{s}^{-1}$. However, no head models were incorporated in Tham et al. [51]'s simulation and hence the analyses were restricted to mechanical responses of the helmet without any insights to head or brain injuries. Another study by Yang and Dai [60] focused on evaluation of the rear effect by having the helmeted FE head model impacted by bullet at different impact angles, while Long et al. [29] studied the effectiveness of a conventional construction helmet in impact scenarios as well as the effectiveness of different construction helmet shapes, namely the conventional uneven shape and smoothen helmet. The severity of head responses were then assessed in both the studies using head injury criterion (HIC). Of late, focuses have also been paid to the helmet shell materials $[49,42,30,12,18,19,3]$ and helmet liners or cushioning system [34,15]. Similarly, Salimi Jazi et al. [44] studied the effect of helmet padding materials and investigated upon the head injury sustained in ballistic impacts, while Tan et al. [48] had performed both experimental tests and FE simulations on helmeted Hybrid III headform using spherical projectile and found that foam cushioning system would help to reduce the head acceleration. Similar results have been observed in the most recent ballistic FE study by Pintar et al. [41], in which skull and brain responses (in terms of percentage of the elemental volume exceeding the selected thresholds to the entire volume) were determined using experimental helmet-to-head contact forces as boundary conditions in the simulations of frontal, rear, lateral impacts on a finite element head model (FEHM) equipping with two helmet liners. However, all these previous studies might have oversimplified the modeling and simulations of the ballistic impacts. Moreover, some of these works had their own individual emphasis on either the impact direction or helmet interior cushioning material. 
In order to determine the severity of the head injuries sustained from ballistic impact and to investigate the effectiveness of the cushioned combat helmet in protecting the head from ballistic impact, series of ballistic impact simulations (frontal, lateral, rear and top) of FMJ bullet on an anatomically detailed subject-specific FEHM, which are based on National Institute of Justice (NIJ) test standard [37], were performed for a duration of $4 \mathrm{~ms}$. The interior cushioning systems included in this current study were namely strap-netting system (in Helmet 1) and Oregon Aero (OA) interior foam cushioning system (in Helmet 2). Additional case of top impact, which resembles the military personnel in the prone position with his or her face facing the ground, while withstanding a gun shot at the helmet, was also included in the analysis for a more complete and comprehensive understanding of head injuries in ballistic impact on helmet. Unlike some of the previous works, the current study adopted some realistic, advanced modeling techniques and boundary conditions in order to simulate the scenario as similar as possible to that of the real life. For example, the study included the realistic modeling of the pre-stressed head and helmet liners prior to the ballistic impacts and the deformed FMJ bullet. Moreover, both inter-ply delamination and intra-lamina damage of the helmet laminate are modeled in our study so as to simulate the ballistic impacts as realistic as possible.

\section{Methods and Materials}

\subsection{Model Development and Model Description}

Geometrical information of the human skull and brain were obtained from axial computed tomography (CT) and magnetic resonance imaging (MRI) images of a 51-year-old Caucasian male subject, with high in-plane resolution, respectively. These medical images were imported 
into Mimics v13.0-v14.0 (Materialise, Leuven, Belgium) for segmentation and reconstruction of the FE model of human head and brain, which comprises the skeletal skull, nasal septal cartilage, nasal lateral cartilage, with the overlying soft tissue, the cerebrospinal fluid (CSF), the white and gray matters of cerebrum, cerebellum, the ventricular system, the midbrain, the brainstem as well as the air-containing sinuses. The various components of the head model can be seen in the midsagittal views in Figure 1. One of the drawbacks of the current head model is that it does not have intracranial membranes as these are difficult to be identified in medical images. A semiautomatic meshing technique was employed in HyperMesh v10.0 (Altair HyperWorks, Troy, MI, USA) to optimize between computational efficiency and element quality, with the average element size of $1.57 \mathrm{~mm}$ and aspect ratio of 1.61. It shall be noted that mesh convergence study was not performed due to the complexity of the model's meshes. However, this was justifiable as the mesh size in the FEHM was comparable or relatively smaller than other existing head models. It should be also noted that the FEHM was validated against the ICP and relative displacement data of three cadaveric experiments in Tse et al. [53]. More details on the development and validation of the FEHM can be found in Tse et al. [53].

Similar to the head model, the advanced combat helmet $(\mathrm{ACH})$ model was reconstructed from axial CT images. On the other hand, the two interior cushioning systems (OA foam and strap-netting) were created based on measurements. Both models of the ACH and interior cushioning systems were meshed with linear hexahedral elements while the straps in Helmet 1 were modeled with linear quadrilateral shell elements with $1.5 \mathrm{~mm}$ thickness (Figure 1).

The $8.2 \mathrm{~g}, 9 \mathrm{~mm}$ FMJ bullet, which is made up of a cartridge brass outer shell and a filling of pure lead within, was used in the NIJ ballistic simulations. Further geometrical details of the FMJ bullet can be found in Tham et al. [51]'s study. 
The series of ballistic impact simulations (frontal, lateral, rear and top) of FMJ bullet on the subject-specific FEHM, were performed for a duration of $4 \mathrm{~ms}$ using the explicit code in Abaqus v6.10 (SIMULIA, RI, USA). The interior cushioning systems were namely strap-netting system (in Helmet 1) and OA interior foam cushioning system (in Helmet 2).

\subsection{Material Properties}

All the skeletal tissues such as cartilages, teeth and cervical vertebrae were modeled as linear elastic, isotropic materials while the brain tissues were assumed to be linear viscoelastic. As for the helmet-liner assembly, the composite layers of the $\mathrm{ACH}$ were broken into different "plates" [48] and were modeled as linear elastic but anisotropic material properties, whilst the various components in the two interior cushioning systems were obtained from the in-house experiments in our previous work [48]. The FMJ bullet for the NIJ simulations had mechanical properties of brass and lead. The material properties of the various components in the helmetcushion-FEHM assembly were summarized in Table 1.

Table 1: Material properties of both the intracranial and extracranial components used in the models.

\begin{tabular}{|c|c|c|c|c|c|}
\hline & \multirow[b]{2}{*}{ Components } & \multicolumn{3}{|l|}{ Material Properties } & \multirow[b]{2}{*}{$\begin{array}{c}\text { Refe } \\
\text { renc } \\
\text { es }\end{array}$} \\
\hline & & $\begin{array}{l}\text { Young's Modulus, E (MPa) / Shear Modulus, } \\
\text { G (MPa) } \\
\qquad G(t)=G_{\infty}+\left(G_{0}-G_{\infty}\right) e^{-\beta t *}\end{array}$ & $\begin{array}{c}\text { Poisson's } \\
\text { ratio, v }\end{array}$ & $\begin{array}{l}\text { Density, } \\
\rho(\mathrm{kg} / \mathrm{m} \\
\left.\mathrm{m}^{3}\right)\end{array}$ & \\
\hline \multirow[t]{6}{*}{ Head } & Brainstem & $G_{0}=0.0225 \mathrm{MPa}, G_{\infty}=0.0045 \mathrm{MPa}, \beta=80 \mathrm{~s}^{-1}$ & 0.4996 & $1.06 \mathrm{E}-06$ & {$[20]$} \\
\hline & $\begin{array}{l}\text { Cerebral } \\
\text { Peduncle }\end{array}$ & $G_{0}=0.0225 \mathrm{MPa}, G_{\infty}=0.0045 \mathrm{MPa}, \beta=80 \mathrm{~s}^{-1}$ & 0.4996 & $1.06 \mathrm{E}-06$ & {$[20]$} \\
\hline & Cerebellum & $G_{0}=0.034 \mathrm{MPa}, G_{\infty}=0.0064 \mathrm{MPa}, \beta=700 \mathrm{~s}^{-1}$ & 0.4996 & $1.04 \mathrm{E}-06$ & {$[4,61$} \\
\hline & CSF & $\begin{array}{c}E=1.314 \text { (Equivalent value based on } E= \\
3 K(1-2 v) \text { using } K=2190 \mathrm{MPa}, v=0.4999 \\
[4,61])\end{array}$ & 0.4999 & $1.04 \mathrm{E}-06$ & $\begin{array}{c}{[4,61} \\
]\end{array}$ \\
\hline & Gray Matter & $G_{0}=0.034 \mathrm{MPa}, G_{\infty}=0.0064 \mathrm{MPa}, \beta=700 \mathrm{~s}^{-1}$ & 0.4996 & $1.04 \mathrm{E}-06$ & {$[61,4$} \\
\hline & Lateral & $E=30$ & 0.45 & $1.50 \mathrm{E}-06$ & [58] \\
\hline
\end{tabular}




\begin{tabular}{|c|c|c|c|c|c|c|c|c|c|c|}
\hline \multicolumn{11}{|c|}{ Cartilage } \\
\hline & $\begin{array}{l}\text { Septum } \\
\text { Cartilage }\end{array}$ & \multicolumn{5}{|c|}{$E=9$} & \multicolumn{2}{|c|}{0.32} & $1.50 \mathrm{E}-06$ & {$[17]$} \\
\hline & Bone & \multicolumn{5}{|c|}{$E=8000$} & \multicolumn{2}{|c|}{0.22} & $1.21 \mathrm{E}-06$ & {$[61]$} \\
\hline & Soft Tissues & \multicolumn{5}{|c|}{$E=16.7$} & \multicolumn{2}{|c|}{0.46} & $1.04 \mathrm{E}-06$ & $\begin{array}{c}{[24,6} \\
1]\end{array}$ \\
\hline & Tooth & \multicolumn{5}{|c|}{$E=2070$} & \multicolumn{2}{|c|}{0.3} & $2.25 \mathrm{E}-06$ & $\begin{array}{c}{[40,5} \\
0]\end{array}$ \\
\hline & Ventricles & \multicolumn{5}{|c|}{$\begin{array}{c}E=1.314 \text { (Equivalent value based on } E= \\
3 K(1-2 v) \text { using } \mathrm{K}=2190 \mathrm{MPa}, v=0.4999 \\
[4,61])\end{array}$} & \multicolumn{2}{|c|}{0.4999} & $1.04 \mathrm{E}-06$ & {$[4,61$} \\
\hline & White Matter & \multicolumn{5}{|c|}{$G_{0}=0.041 \mathrm{MPa}, G_{\infty}=0.0078 \mathrm{MPa}, \beta=700 \mathrm{~s}^{-1}$} & \multicolumn{2}{|c|}{0.4996} & $1.04 \mathrm{E}-06$ & [4] \\
\hline \multirow[t]{2}{*}{$\mathrm{ACH}$} & & $\begin{array}{l}\mathbf{E}_{11} \\
(\mathbf{M P a})\end{array}$ & $\begin{array}{l}\mathbf{E}_{22} \\
(\mathbf{M P a})\end{array}$ & $\begin{array}{l}\mathbf{E}_{33} \\
(\mathbf{M P a})\end{array}$ & $\begin{array}{l}\mathbf{G}_{12} \\
(\mathbf{M P a})\end{array}$ & $\begin{array}{l}\mathbf{G}_{13} / \\
\mathbf{G}_{23} \\
\text { (MP } \\
\text { a) }\end{array}$ & $v_{12}$ & $\begin{array}{l}v_{13} \\
/ v_{2} \\
3\end{array}$ & $\begin{array}{c}\rho(\mathbf{k g} / \mathbf{m} \\
\left.\mathbf{m}^{3}\right)\end{array}$ & $\begin{array}{l}\text { Refe } \\
\text { renc } \\
\text { es }\end{array}$ \\
\hline & $\begin{array}{l}\text { Helmet } \\
\text { Shells }\end{array}$ & 18000 & 18000 & 4500 & 770 & 2600 & 0.25 & $\begin{array}{l}0.3 \\
3\end{array}$ & 1230 & {$[48]$} \\
\hline \multirow{6}{*}{$\begin{array}{c}\text { Inter } \\
\text { ior } \\
\text { Cush } \\
\text { ionin } \\
\text { g } \\
\text { Syst } \\
\text { ems }\end{array}$} & $\begin{array}{c}\text { Cross Straps } \\
\text { (Helmet 1) }\end{array}$ & \multicolumn{5}{|c|}{$E=60$} & \multicolumn{2}{|c|}{0.25} & 400 & {$[48]$} \\
\hline & $\begin{array}{l}\text { Front } \\
\text { Cushion } \\
\text { (Helmet 1) } \\
\end{array}$ & \multicolumn{5}{|c|}{$E=18$} & \multicolumn{2}{|c|}{0.25} & 200 & {$[48]$} \\
\hline & $\begin{array}{l}\text { Main Loop } \\
\text { (Helmet 1) }\end{array}$ & \multicolumn{5}{|c|}{$E=60$} & \multicolumn{2}{|c|}{0.25} & 400 & {$[48]$} \\
\hline & $\begin{array}{c}\text { Netting } \\
\text { (Helmet 1) }\end{array}$ & \multicolumn{5}{|c|}{$E=60$} & \multicolumn{2}{|c|}{0.25} & 400 & {$[48]$} \\
\hline & $\begin{array}{c}\text { Rear Cushion } \\
\text { (Helmet 1) }\end{array}$ & \multicolumn{5}{|c|}{$E=18$} & \multicolumn{2}{|c|}{0.25} & 200 & {$[48]$} \\
\hline & $\begin{array}{l}\text { OA Foams } \\
\text { (Helmet 2) }\end{array}$ & \multicolumn{7}{|c|}{ Direct compression data from experiment } & 164 & {$[48]$} \\
\hline \multirow[t]{2}{*}{$\begin{array}{l}\text { Proje } \\
\text { ctile }\end{array}$} & $\begin{array}{c}\text { Cartridge } \\
\text { Brass of FMJ } \\
\text { Bullet } \\
\end{array}$ & \multicolumn{5}{|c|}{$E=110000$} & \multicolumn{2}{|c|}{0.375} & 8520 & \\
\hline & $\begin{array}{c}\text { Lead Core of } \\
\text { FMJ Bullet }\end{array}$ & \multicolumn{5}{|c|}{$G=200$} & \multicolumn{2}{|r|}{-} & 11840 & \\
\hline
\end{tabular}

* This equation describes the shear characteristics of this linear viscoelastic behavior of the brain tissues, where $G_{0}$ and $G_{\infty}$ are the short and long term shear moduli respectively while $\beta$ is the decay factor and $\mathrm{t}$ denotes time.

\subsection{Failure Modeling of Helmet and FMJ Bullet}


In this study, both the modeling of property degradation for the $\mathrm{ACH}$ as well as the interlaminar failure using surface traction criteria were included [48]. Moreover, the fabric-reinforced aramid laminates of the helmet shell were modeled using the Hashin Fabric Criterion that takes into account bi-directional strength of the fibers as woven into a fabric laminate [48].

As for the FMJ bullet, in order to allow the cartridge brass material to fail under the large deformation that will be anticipated for the FMJ bullet upon impact with the $\mathrm{ACH}$, the exterior cartridge brass material was modeled by Johnson Cook plasticity hardening and damage initiation criterion [21]. The Mie-Grüneisen hydrodynamic equation of state material model was used to model the lead core [2], with all the material constants and parameters for the cartridge brass's Johnson-Cook model and lead core's Mie-Grüneisen hydrodynamic equation of state material model are provided in Table 2. Hourglass control was used for the hexahedral elements of the FMJ bullet, helmet shells and interior foams and the hourglass energies for all the impact cases are less than $15 \%$ of the total energy at the peak force, which is considered acceptable for high speed impacts.

Table 2: Material constants in failure modeling of FMJ bullet.

\begin{tabular}{|c|c|c|c|c|c|c|c|c|}
\hline Components & & & Materi & Const: & For $\mathbf{F}$ & e Mo & & \\
\hline & & & ants iI & ohnsol & ook $\mathrm{S}$ & Rate & lening & \\
\hline & $\mathbf{A}$ & B & n & $\mathbf{M}$ & $\begin{array}{l}\mathbf{T}_{\mathbf{m}} \\
(\mathbf{K})\end{array}$ & $\begin{array}{l}T_{\text {trans }} \\
(\mathbf{K})\end{array}$ & C & $\begin{array}{c}\varepsilon_{0} \\
\left(\mathbf{s}^{-1}\right)\end{array}$ \\
\hline Cartridge Brass & 112 & 505 & 0.42 & 1.68 & 1189 & 373 & 0.009 & 1 \\
\hline & & Con & ts in $J$ & nson-C & Dan & Initia & Criteri & \\
\hline & $\mathbf{d}_{1}$ & $\mathbf{d}_{2}$ & $\mathbf{d}_{3}$ & $\mathbf{d}_{4}$ & $d_{5}$ & $\begin{array}{l}\mathbf{T}_{\mathbf{m}} \\
(\mathbf{K})\end{array}$ & $\begin{array}{c}\mathbf{T}_{\text {trans }} \\
(\mathbf{K})\end{array}$ & $\begin{array}{c}\mathcal{E}_{0} \\
\left(\mathbf{s}^{-1}\right)\end{array}$ \\
\hline & 0.54 & 4.89 & 3.03 & 0.014 & 1.12 & 1189 & 373 & 1 \\
\hline Lead Core & Cons & ( & $\begin{array}{l}\text { rüneis } \\
\text { ear Us }\end{array}$ & $\begin{array}{l}\text { hydro } \\
\text { p Hug }\end{array}$ & $\begin{array}{l}\text { lamic } \\
\text { t for }\end{array}$ & ion & & $\begin{array}{l}\text { ic He } \\
\text { acity } \\
-1 \cdot K^{-1}\end{array}$ \\
\hline
\end{tabular}


$\mathrm{c}_{0}(\mathrm{~cm} / \mu \mathrm{s})$

0.2006

\section{$\mathbf{s}$}

1.429
$\Gamma_{0}$

2.60

\subsection{Contacts and Boundary Conditions}

Contact conditions such as tangential sliding boundary condition using penalty friction formulation with the coefficient of friction of $0.2[33,26,24]$ as well as normal hard contact pressure-overclosure boundary condition, were applied on the brain-CSF and skull-CSF interfaces. All the interfaces between other intracranial contents and those between skull, cartilages and soft tissues were implemented with tie constraints. The interfaces between the helmet and interior cushions as well as between the cushions and head were imposed with normal hard contact pressure-overclosure boundary condition and the static-kinetic exponential decay frictional sliding contact (coefficient of static friction $=0.5$; coefficient of kinetic friction=0.375). The boundary conditions at the base of the helmet-cushion-FEHM assembly would be modeled according to the NIJ-STD-0106.00 [37] requirement for ballistic helmets in such a way that the head has to be rigidly mounted on a base which is free to move in the direction of motion of the test bullet. Table 3 shows boundary conditions that were applied at the base of the helmet-cushion-FEHM assembly for the respective cases of NIJ ballistic simulations. It should be noted that the boundary conditions for top impact in Table 3 are not required by NIJ-STD-0106.00 [37]. However, this top impact case was included in the analysis for a more complete and comprehensive understanding of head injuries in ballistic impact on helmet. In this case, the military personnel could be treated as if being in the prone position with his or her face facing the ground, while withstanding a gun shot at the helmet. Due to the large body mass inertia and frictional force between the body and the ground, the base of the neck would neither be able to move in the direction of bullet, nor to rotate along the axis of impact direction. As for 
the initial condition, an initial velocity of $358 \mathrm{~m} \cdot \mathrm{s}^{-1}$ (average of the range of $343 \mathrm{~m} \cdot \mathrm{s}^{-1}-373 \mathrm{~m} \cdot \mathrm{s}^{-1}$ ) was prescribed to the entire FMJ bullet [1], for each of the impact directions and helmet liner configuration.

Table 3: Boundary conditions for the NIJ ballistic impact simulations.

\begin{tabular}{ll} 
Impact Direction & $\begin{array}{l}\text { Displacement Constraints at the Base of } \\
\text { the Helmet-Cushion-FEHM Assembly }\end{array}$ \\
\hline \hline Front & $\mathrm{U}_{2}=0 ; \mathrm{U}_{3}=0 ; \theta_{1}=0 ; \theta_{3}=0$ \\
Side & $\mathrm{U}_{1}=0 ; \mathrm{U}_{3}=0 ; \theta_{2}=0 ; \theta_{3}=0$ \\
Rear & $\mathrm{U}_{2}=0 ; \mathrm{U}_{3}=0 ; \theta_{1}=0 ; \theta_{3}=0$ \\
Top & $\mathrm{U}_{1}=0 ; \mathrm{U}_{2}=0 ; \mathrm{U}_{3}=0 ; \theta_{3}=0$ \\
\hline \hline
\end{tabular}

where U denotes linear displacement;

$\theta$ denotes rotational displacement;

subscript 1 denotes the anterior-posterior direction;

subscript 2 denotes the right-left direction and;

subscript 3 denotes the inferior-superior direction.

\subsection{Simulation Steps}

Prior to the ballistic impact, it is necessary to ensure the cushioned helmet fits well onto the head as well as the head and helmet cushions are pre-stressed by the helmet's own weight and securing straps. Figure 2a shows the entire sequence of the simulations which consist of various simulation steps. In the initial step, the helmets' interior cushion systems were preformed to fit well onto the interior surface of the helmet shell. It should be noted that only the conformed shapes of the helmets' interior cushion systems were retained without any stress-state propagation to the subsequent helmet fitting step. This was then followed by a helmet fitting step 
of $4 \mathrm{~ms}$ where the helmet was loaded quasi-statically onto the head, with only the cushions and head's stress-state propagation activated for the subsequent ballistic step. This was to simulate the military personnel wearing and fitting into the combat helmet. The head's contact force history of the fitting step was monitored to ensure the pressure on the head is not over-pressured or overly loaded (Figure 2b). The contact forces established at the end of the helmet fitting step were approximately $15 \mathrm{~N}$ and $35 \mathrm{~N}$ for Helmet 1 and Helmet 2, respectively. These values were considered reasonable since the combined mass of the helmet and interior cushions is approximately $1.5 \mathrm{~kg}$ which would constitute a stress-free weight of $15 \mathrm{~N}$ on the head. The resulting contact forces implied a good fit of the soldier's head with the cushioning systems and the helmet. It should be highlighted that both the conformed shapes and the stress-state of all the components were retained for the last step of ballistic impact where a FMJ bullet impacted upon the helmet (Figure 2a).

\subsection{Parameters for Data Analysis}

Biomechanical metrics such as skull von Mises stress, ICP, strain and shear strain, which can neither be measured easily nor in vivoly by experimental techniques, were extracted from the ballistic simulations and compared for both the helmet configurations. Based on these biomechanical values, evaluation of TBIs could be carried out for each type of the interior cushioning system and impact direction by comparing the predicted biomechanical metrics with various failure data reported in literature $[57,35,62,32]$.

In order to analyze potential skull fractures, an average value of von Mises stresses of $75 \mathrm{MPa}$ was used as the yielding limit of the skull bone according to the reported range in McElhaney et al. [32]. For each impact direction and helmet cushion type, maximum skull von 
Mises stress was extracted from the FE simulations and was compared with this average literature-reported failure data of $75 \mathrm{MPa}$ [32]. The injury of the brain could be assessed with the cerebral maximum and minimum ICP as well as the peak magnitudes of principal and shear strains of the central nervous system (i.e. white matter and brainstem). According to the literature, an ICP injury criterion, proposed by Ward et al. [57] based on combined numerical and experimental investigation of live animals and human cadavers, states that serious or fatal brain injury occurs when the peak ICP exceeds $235 \mathrm{kPa}$, while no/minor brain injury occurs when the ICP is below $173 \mathrm{kPa}$. On the other hand, the strain-based injury thresholds for axonal injuries are 0.20 (for principal strain) and 0.24 (for shear strain) $[13,35,62]$. Maximum principal strain of more than 0.20 at strain rates of $50 \mathrm{~s}^{-1}$ or more had been considered as injurious load by Morrison et al. [35] in the prediction of central nervous system injuries such as diffuse axonal injury (DAI) and cell death, while shear strains based injury threshold of 0.24 have been proposed by Zhang et al. [62] as a predictor with $80 \%$ possibility of brainstem injury. Table 4 summarizes the various thresholds for head injuries from 
Table 4: Head injuries thresholds used in the current study.

\begin{tabular}{|c|c|c|}
\hline & Parameter & Thresholds \\
\hline $\begin{array}{l}\text { Skull } \\
\text { Fracture }\end{array}$ & Von Mises Stress & $\begin{array}{l}\text { McElhaney et al. (1970) [32] } \\
\text { Average of } 75 \mathrm{MPa} \rightarrow \text { Skull fracture }\end{array}$ \\
\hline \multirow[t]{3}{*}{$\begin{array}{l}\text { Brain } \\
\text { Injury }\end{array}$} & $\begin{array}{l}\text { Intracranial Pressure } \\
\text { (ICP) }\end{array}$ & $\begin{array}{l}\text { Ward et al. (1980)[57] } \\
>235 \mathrm{kPa} \rightarrow \text { Serious or fatal brain injury } \\
<173 \mathrm{kPa} \rightarrow \text { Minor or no injury }\end{array}$ \\
\hline & Principal Strain & $\begin{array}{l}\text { Galbraith et al. (1993) [13] } \\
>0.25 \rightarrow \text { Structural failure } \\
>0.20 \rightarrow \text { Functional deficit and irreversible injury } \\
<0.10 \rightarrow \text { Reversible injury } \\
\text { Morrison et al. [35] } \\
>0.20 \rightarrow \text { Considered as injurious threshold with possibility of sustaining cell } \\
\text { death and DAI. }\end{array}$ \\
\hline & Shear Strain & $\begin{array}{l}\text { Zhang et al. [62] } \\
>0.24 \rightarrow 80 \% \text { probability of moderate TBI } \\
>0.19 \rightarrow 50 \% \text { probability of moderate TBI } \\
>0.14 \rightarrow 25 \% \text { probability of moderate TBI }\end{array}$ \\
\hline
\end{tabular}

\section{Results}

\subsection{Numerical Simulations of Ballistic Impacts from Various Directions}

\subsubsection{Skull stress}

Von Mises stress has been commonly utilized in numerous studies in the literature $[24,60]$, for the measurement of skeletal stress intensity. In this study, von Mises stress was chosen as the biomechanical metrics for analysis of the skull in the ballistic impact as this parameter serves as an equivalent value for gauging the intensity of impact to the skull. Figure 3 shows the maximum von Mises stress of the skull experienced in the four various ballistic impact directions for the two helmet configurations. It was noted that the peak skull stresses for all the cases only occurred on the exterior surface of the skull where the impact sites were. It was also observed that the peak skull stresses occurred at approximately less than $0.3 \mathrm{~ms}$ after impact for all the 
cases except for the lateral impact cases, in which the skull stresses took approximately $0.6 \mathrm{~ms}$ to reach its peak. Figure 4 shows the comparison of the magnitude of the skull von Mises stresses obtained for various impact directions, indicating that the top impact was the most severe with peak skull stresses reaching up to $15 \mathrm{MPa}$, followed by frontal and lateral impacts of comparable magnitude of stresses, while the rear impact was the least severe.

\section{$\underline{\text { 3.1.2 Intracranial pressure (ICP) }}$}

The maximum and the minimum ICP for all the cases were extracted from the dynamic simulations and their respective locations are shown in Figure 5. It can be seen in Figure 5 that most of these peak (or trough) ICPs occurred at the cerebral cortex (gray matter), except for the top impact case whereby the peak ICPs occurred at the interface between gray matter and white matter for both helmets. Among all the various impact directions, lateral impacts gave the highest ICP (2.23MPa for Helmet $1 ; 1.15 \mathrm{MPa}$ for Helmet 2) while rear impacts resulted in highest negative ICP (-0.877MPa for Helmet 1; -0.908MPa for Helmet 2). It was then followed by frontal impacts and top impacts, with the ICP values for top impacts (maximum ICP: 0.069MPa or minimum ICP: $-0.054 \mathrm{MPa}$ for Helmet 1; maximum ICP: $0.164 \mathrm{MPa}$ or minimum ICP: $-0.104 \mathrm{MPa}$ for Helmet 2). It was found that the magnitude of the ICP is generally lower in the FEHM equipped with Helmet 2 (with OA foam padding), except for the top impact case. The maximum or minimum pressures of the ventricles in the inner brain were also shown for all the cases in Figure 6. The trend of severity in terms of these critical pressure metrics for various impact directions can be seen in Figure 7, with lateral and rear impacts being the most severe whilst the top impacts being the least. 


\subsubsection{Intracranial strains}

Maximum principal strain is another popular metric for brain injury [27]. Figure 8 shows the maximum principal strain and maximum shear strain of white matter, for each impact direction and helmet liner configuration. These maximum strain metrics were found mainly in the white matter tissues underlying the impact site, except for the frontal impact cases with both helmets and the top impact case with Helmet 1. For these cases, maximum strains were concentrated at the anterior tip of the ventriculus lateralis (Figure $8 \mathrm{a} 1,8 \mathrm{a} 2 \& 8 \mathrm{~d} 1$ ). It was noted that the severity sequences in terms of the strain intensities for the two helmet cushioning systems were different. For Helmet 1 (with strap-netting), the rear impact resulted in a peak principal strain of 0.281 and a peak shear strain of 0.474 , while the lateral impact with slightly lower strains, exceeding both the principal and shear strain limits mentioned earlier on $[35,62]$. It was then followed by the frontal impact with strain values falling marginally below the 0.2 principal strain limit and the 0.24 shear strain limit. Like the pressure metrics, the top impact had the least strain values. On the other hand, for Helmet 2 (with OA foam padding), the lateral impact swapped sequence with rear impact, with only lateral impact exceeding the strain thresholds.

Similar trend can be observed for the brainstem in Figure 9; it generally experienced higher strain in lateral impacts than rear impacts, frontal impacts and top impacts, despite the fact that the maximum principal strain in rear impact for Helmet 1 was slightly higher (17\%) than that in lateral impact (Figure 9). The peak principal and shear strains of both the white matter and brainstem were summarized in the bar charts shown in Figure 10. Table 5 shows all the predicted helmet and head responses in helmet configurations (Helmet $1 \&$ Helmet 2) for various impact directions. Table 5: The simulated helmet parameters and head injury metrics for the FEHM with Helmet 1 and Helmet 2 configurations. 
Helmet 1 (with strap-netting)

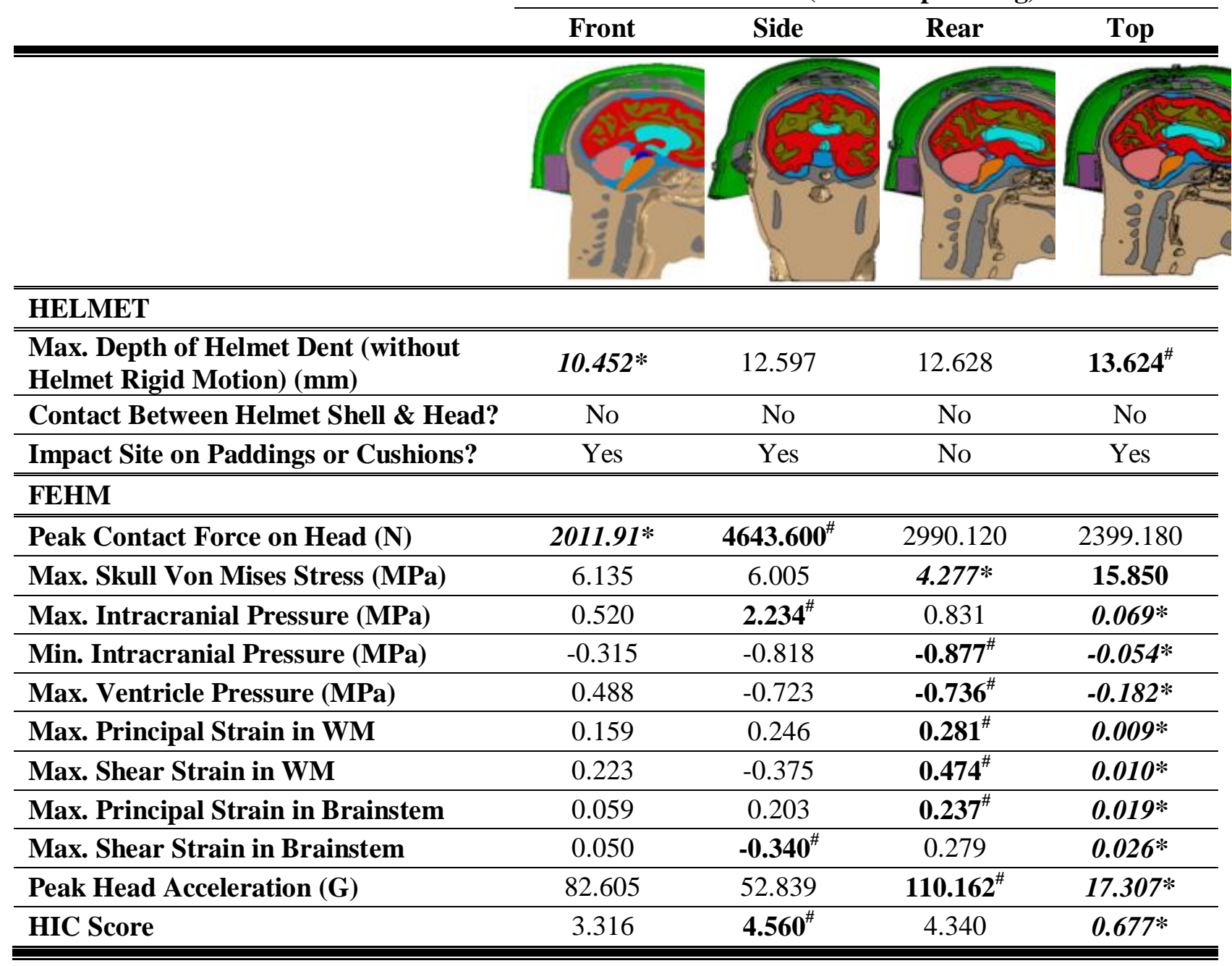

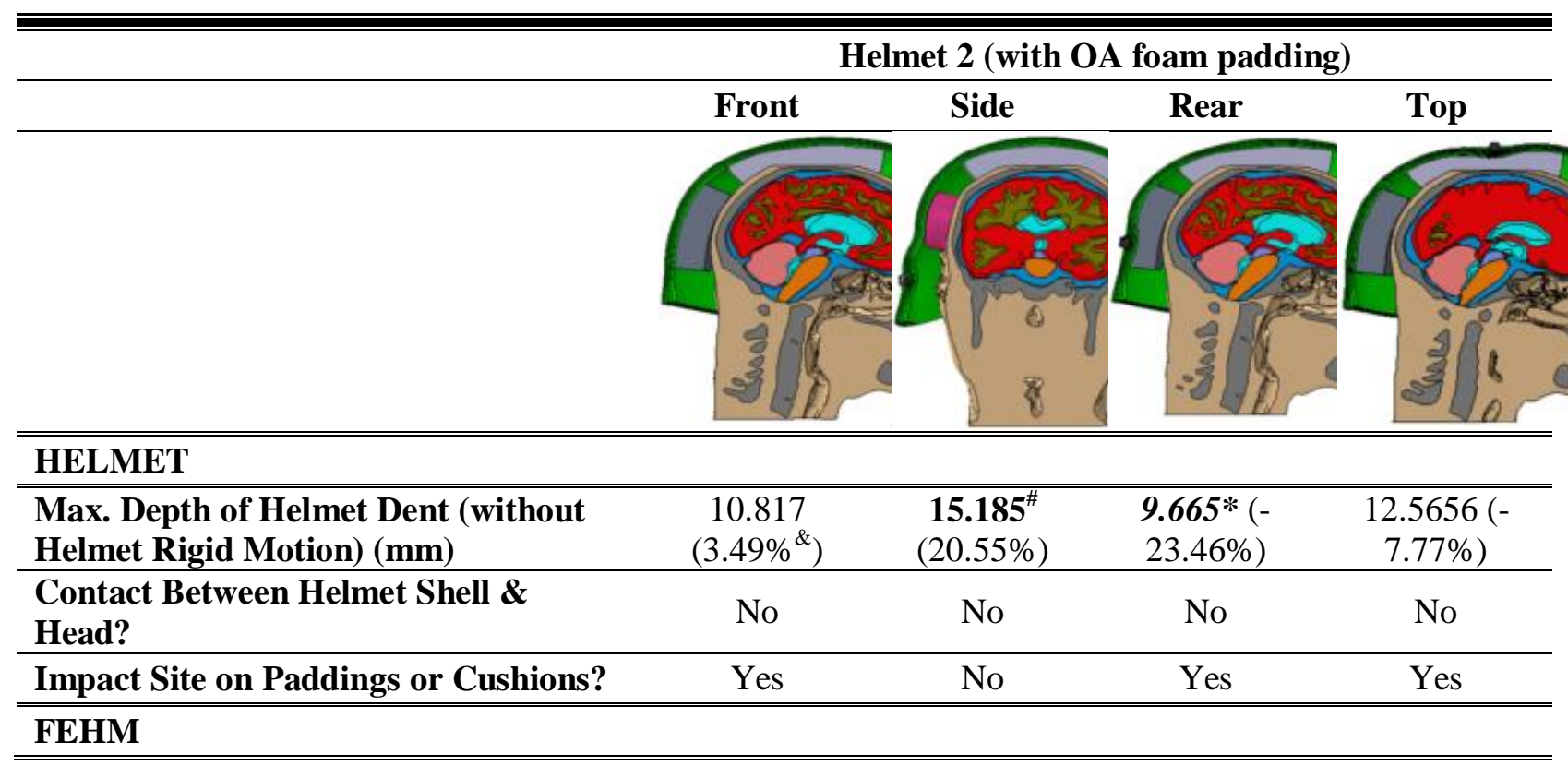




\begin{tabular}{|c|c|c|c|c|}
\hline Peak Contact Force on Head (N) & $\begin{array}{c}335.492 *(- \\
83.32 \%) \\
\end{array}$ & $\begin{array}{c}1075.510(- \\
76.84 \%) \\
\end{array}$ & $\begin{array}{c}557.868(- \\
81.34 \%) \\
\end{array}$ & $\begin{array}{c}\mathbf{2 0 1 4 . 0 2}^{\#}(- \\
16.05 \%)\end{array}$ \\
\hline Max. Skull Von Mises Stress (MPa) & $\begin{array}{c}3.141(- \\
48.80 \%)\end{array}$ & $\begin{array}{c}3.212(- \\
46.51 \%)\end{array}$ & $\begin{array}{l}2.166 *(- \\
49.36 \%)\end{array}$ & $\begin{array}{l}\mathbf{1 4 . 1 5}^{\#}(- \\
10.73 \%)\end{array}$ \\
\hline Max. Intracranial Pressure (MPa) & $\begin{array}{c}0.428(- \\
17.73 \%)\end{array}$ & $\begin{array}{l}\mathbf{1 . 1 5 1}^{\#}(- \\
48.48 \%)\end{array}$ & $\begin{array}{c}0.729(- \\
12.34 \%) \\
\end{array}$ & $\begin{array}{c}\mathbf{0 . 1 6 4 3 *} \\
(138.22 \%) \\
\end{array}$ \\
\hline Min. Intracranial Pressure (MPa) & $\begin{array}{l}-0.230(- \\
27.03 \%)\end{array}$ & $\begin{array}{l}-0.539(- \\
34.11 \%)\end{array}$ & $\begin{array}{c}\mathbf{- 0 . 9 0 8} \# \\
(3.63 \%) \\
\end{array}$ & $\begin{array}{l}-0.1035 \% \\
(91.63 \%)\end{array}$ \\
\hline Max. Ventricle Pressure (MPa) & $\begin{array}{c}0.490 \\
(0.41 \%) \\
\end{array}$ & $\begin{array}{c}\mathbf{0 . 5 0 0}^{\#}(- \\
169.19 \%) \\
\end{array}$ & $\begin{array}{l}-0.383(- \\
48.00 \%)\end{array}$ & $\begin{array}{l}0.1361 *(- \\
174.90 \%)\end{array}$ \\
\hline Max. Principal Strain in WM & $\begin{array}{c}0.131(- \\
17.52 \%)\end{array}$ & $\begin{array}{c}\mathbf{0 . 2 3 0} \#(- \\
6.44 \%) \\
\end{array}$ & $\begin{array}{c}0.122(- \\
56.69 \%) \\
\end{array}$ & $\begin{array}{c}0.03792 * \\
(335.86 \%) \\
\end{array}$ \\
\hline Max. Shear Strain in WM & $\begin{array}{c}0.194(- \\
12.96 \%)\end{array}$ & $\begin{array}{c}\mathbf{0 . 4 3 6}^{\#}(- \\
216.34 \%) \\
\end{array}$ & $\begin{array}{c}0.225(- \\
52.60 \%) \\
\end{array}$ & $\begin{array}{c}0.05092 * \\
(391.03 \%) \\
\end{array}$ \\
\hline Max. Principal Strain in Brainstem & $\begin{array}{l}0.053(- \\
9.58 \%)\end{array}$ & $\begin{array}{l}\mathbf{0 . 1 5 8}^{\#}(- \\
22.05 \%)\end{array}$ & $\begin{array}{c}0.111(- \\
53.33 \%)\end{array}$ & $\begin{array}{c}\mathbf{0 . 0 3 5 9 7} \\
*(87.93 \%) \\
\end{array}$ \\
\hline Max. Shear Strain in Brainstem & $\begin{array}{l}0.047(- \\
7.33 \%)\end{array}$ & $\begin{array}{c}\mathbf{0 . 2 5 1}^{\#}(- \\
173.85 \%) \\
\end{array}$ & $\begin{array}{c}0.133(- \\
52.44 \%)\end{array}$ & $\begin{array}{l}0.04474 * \\
(69.09 \%)\end{array}$ \\
\hline Peak Head Acceleration (G) & $\begin{array}{l}45.479(- \\
44.94 \%)\end{array}$ & $\begin{array}{c}\mathbf{5 2 . 8 0 2}^{\#}(- \\
0.07 \%)\end{array}$ & $\begin{array}{l}52.655(- \\
52.20 \%)\end{array}$ & $\begin{array}{c}15.855 *(- \\
8.39 \%)\end{array}$ \\
\hline HIC Score & $\begin{array}{c}3.360 \\
(1.33 \%) \\
\end{array}$ & $\begin{array}{c}\mathbf{6 . 1 3 0}^{\#} \\
(34.43 \%) \\
\end{array}$ & $\begin{array}{c}4.294(- \\
1.06 \%)\end{array}$ & $\begin{array}{c}\mathbf{0 . 7 9 2} * \\
(17.00 \%) \\
\end{array}$ \\
\hline
\end{tabular}

* presents the minimum absolute value in the same helmet with different impact directions.

\# presents the maximum absolute value in the same helmet with different impact directions.

\& The value inside the parenthesis denotes percentage difference $(\%)$ between the Helmet $1 \&$ Helmet 2, with Helmet 1 as the basis of comparison.

4. Discussions

\subsection{Validation of the FEHM in short duration, low mass and high speed ballistic impacts}

To the authors' best knowledge, none of the reported FEHMs has been validated for low mass and high speed impacts since there is no such ballistic data available. The only available experimental pressure data for ballistic impacts on protected cadaveric heads are by Sarron et al. who performed ballistic impact tests on both the silicone-filled human dry skulls and full human cadaveric heads [45,46]. In the past, Aare and Kleiven [1] benchmarked their simulated ICP magnitudes with the experimental values reported by Sarron et al. [45], while Yang and Dai [60] compared the simulated skull stress and brain pressure with Aare and Kleiven [1]. Despite the 
numerical values were of a few time difference, they found that the observed trend of decreasing skull stress and brain pressure with larger impact angle is similar to that of Aare and Kleiven [1].

The present study chose to only benchmark with the experimental pressure values and ranges of Sarron et al.'s later work [46] since it is the only available experimental pressure data when the helmeted heads were impacted by the same $9 \mathrm{~mm}$ FMJ projectile with similar impact energy (600J). Similar to Sarron et al. [46]'s experimental work, pressure values in the lateral impact in the NIJ simulations have been extracted from the head centre of gravity (CG) and compared with the experimental pressures in the middle of the silicone-filled dry skulls. It should be noted that the investigated distances between the polyethylene plate (which acted as a helmet) and the skull were 12-15mm in Sarron et al. [46]'s experiments while the helmet-head distances in the simulated NIJ lateral impacts were around $30 \mathrm{~mm}$ at the impact site. The experimental range of internal pressure was reported to be from $0.092 \mathrm{MPa}$ (corresponding to $15 \mathrm{~mm}$ distance) to $1.261 \mathrm{MPa}$ (corresponding to $12 \mathrm{~mm}$ distance), whilst the present simulated peak ICPs at the head's CG were $0.0275 \mathrm{MPa}$ and $0.0266 \mathrm{MPa}$ for Helmet 1 and Helmet 2 respectively. These were in agreement with Sarron et al. [46]'s observation of lower internal pressure with increasing helmet-head distance and as such, the simulated ICPs were therefore expected to be way below 0.092 MPa (corresponding to $15 \mathrm{~mm}$ distance). In addition, the present study also compared the simulated ventricular pressures with those measured in Sarron et al. [46]'s experimental nonpenetrating ballistic impacts of similar projectile on "helmeted" full cadaveric human heads. It can be seen that the peak ventricular pressures obtained from simulations (0.136MPa$0.500 \mathrm{MPa}$ ), which occurred in the third ventricle, fell within the experimental ventricular pressure range of $0.080 \mathrm{MPa}-1.2 \mathrm{MPa}$. Both the head centroidal pressure and ventricular pressure obtained from the simulations agreed reasonably well with those in the cadaveric experiments of 
the silicone-filled dry skulls and fresh heads. This intracranial metrical benchmarking provided us a certain degree of confidence in using the FEHM in short duration, low mass and high speed ballistic impacts.

\subsection{Effects of impact direction and different cushion systems}

The effects of impact direction and different cushion systems on the head's biomechanical metrics were discussed based on the types of injuries. Regarding extracranial injuries such as skull fracture, the top impacts caused the highest maximum skull von Mises stresses (approximately 15MPa) (Table 5 \& Figure 4).

Based on the von Mises yield criterion of $75 \mathrm{MPa}$ used in this study, no severe skull fractures would be expected for all the impact directions and for both helmet configurations. It could be inferred that both helmets were effective in mitigating bony injuries in all impact directions, with Helmet 2 (with OA foam padding) being more effective in reducing the impact stresses on the skull (the percentage of reduction up to more than $40 \%$ for frontal, lateral and rear impacts while $10.73 \%$ for top impacts) (Table $5 \&$ Figure 4). This was consistent with the observation of Pintar et al. [41]'s FE study for the foam padded helmet, despite that the stress limit of 40MPa were observed to be exceeded only for the belt lined helmet in side impacts in Pintar et al. [41]'s FE study.

With regard to intracranial injuries or brain injuries, both helmets failed in protecting the brain from severe or fatal injuries induced by pressure for all impacts except top impacts. ICP has been hypothesized to be one of the most critical biomechanical responses in brain injury since an elevated ICP in head trauma can lead to severe brain damage $[57,59,62]$. The ICP was generally lower in the FEHM equipped with Helmet 2 (with OA foam padding) with the 
exception of top impacts. The results of the top impacts showed a different trend and that would be discussed further in the subsequent paragraph. The FEHM was found to experience the highest maximum ICP in lateral impacts while most severe negative ICP occurred in rear impacts, when equipped with either of the two helmets (Helmet $1 \&$ Helmet 2) (Table 5 \& Figure 7a). This was consistent with Yang and Dai [60]'s observation that the rear impact and the side impact resulted in higher ICPs than frontal impact.

The use of shear strains and principal strains as a measure of brain injury has also become increasingly popular with more published test data $[47,6,35]$ as well as computational studies $[62,10,13]$. Maximum principal strains had been demonstrated by Morrison et al. [35] as a predictor of central nervous system injuries such as diffuse axonal injury (DAI), cell death and neuronal dysfunction while shear strains based injury thresholds have been proposed by Zhang et al. [62] in prediction of possibility of brainstem injury. As for the strain-induced injuries, Helmet 2 tended to give better protection than Helmet 1, with the only exceptional case of top impact. Helmet 1 failed to protect the brain from sustaining irreversible axonal injuries and cell death in both the rear and lateral impacts, with the maximum strains exceeding both the principal strain threshold and shear strain threshold (Table 4 \& Figure 10). Relatively lower strains were found in the brainstem in Helmet 2 configuration, with only the peak principal strain and shear strain in lateral impact case exceeding marginally the principal and shear strain limits (Table $4 \&$ Figure 10). Our FEHM generally experienced the most damaging strains in rear and lateral impacts for both helmet configurations (Table 5 \& Figure 10). This trend was different from that observed in Yang and Dai [60]'s study in 2010 and the discrepancy could be due to the oversimplification in modelling in Yang and Dai [60]'s FE study with no helmet liner or interior cushioning system modelled between the head and helmet. 
Another point to be noted was that the lateral impacts (for both helmets) were more severe than the frontal impacts in terms of the biomechanical metrics. This observation was similar to that seen in the indirect impacts on an unhelmeted head in Wang et al. [56]'s study which analyzed in terms of skull stresses, brain pressure and strains. However, it was in contrary to our earlier observation in the Hybrid III experiments and simulations [48], which was based on head accelerations. This might appear to suggest that the biomechanical metrics do not necessarily correlate kinematics of head's CG, despite the fact that ICP had been proposed to be closely related to head kinematics [62].

As such, the average peak head acceleration and HIC values for various NIJ impact directions and helmet liner configurations were also extracted from the set of nodes near the model's CG and were shown in Figure 11. Despite the scenarios simulated in this study are of ballistic (or low mass-high speed) nature which can be quite different from those seen in crash situations (high mass-low speed), HIC score was still employed in the current study as a quantitative measure for comparison with the trends observed using biomechanical metrics. It could be seen in the comparison between frontal and lateral impact cases with Helmet 1 (with strap-netting) configuration that the higher head acceleration did not necessarily give a higher HIC. Also, when compared the frontal and lateral impacts between the two helmet configurations, HIC scores are generally higher for Helmet 2 configuration and yet the corresponding peak biomechanical metrics seem to be of lower value than those of Helmet 1 configuration. Overall, it is still difficult to draw any concrete conclusion for correlation between metrics and the severity of impact direction. Each individual metric, for example, the maximum values of skull von Mises stress, did not necessarily have the same trend or correlation as the peak values of other metrics (i.e. ICP, principal strain and shear strain). Moreover, the kinematic 
metrics (acceleration and HIC score) did not necessarily correlate with any of the biomechanical metrics. This agreed well with Yang and Dai [60]'s conclusion. However, it could be seen from Table 5 \& Figures $4,7 \& 10$ that the OA foam padded Helmet 2 was generally more protective against skull fracture and pressure-induced as well as strain-induced brain injuries for frontal, lateral and rear impacts.

It can be noted that both the rear impact in strap-netting configuration (Helmet 1) and side impact in foam padding configuration (Helmet 2) were off-interior cushion impacts, in which the bullets hit at regions where the interior helmet surface was not supported by the helmet interior cushioning system. Generally, the off-interior cushion impacts had higher risk of injuring the intracranial contents than the on-interior cushion impacts, as the interior cushions provide an energy dissipation mechanism that helps to mitigate injury for on-interior cushion impacts. Specifically, the off-pad side impact hit on the helmet rim region where the helmet shell was just supported on one side by the pads, causing the most significant helmet dent of $15.2 \mathrm{~mm}$. This confirms that the relationship of the interior cushion to the impact location is one of the significant factors in the severity of head injuries and suggests that helmet liner configuration with more cushions or padding inserts mitigates head injuries resulted from ballistic impacts. Moreover, such helmet liner configuration with more padding inserts of smaller size may be able to eliminate or reduce the blast-induced wave-focusing effect $[36,14,38]$ in the helmet-head subspace during blast exposure.

Despite a different trend seen in top impacts, it should be noted that, unlike the other impacts, top impacts had the neck base restrained in the impact direction. Since the neck is less compliant in its axial compression against the larger torso mass torso as well as the larger frictional force between the soldier's body and the ground if in prone position, than its anterior 
flexion, posterior extension and lateral flexion, such restricted boundary condition was imposed for top impacts. Due to the restrained neck motion in their impact direction, top impacts would have the least movement of the head and relative motion between the skull and brain. As such, the top impacts were at the lowest risk for intracranial brain injuries and yet had most of the impact energy absorbed by the restrained skull without the skull stress exceeding the fracture criterion. The top impact with strap-netting configuration (Helmet 1) resulted in lower peaks in some of the intracranial metrics and larger helmet shell deflection of approximately $13.6 \mathrm{~mm}$. This helmet shell deformation may in turn help to absorb some of the projectile impact energy and mitigate the stress transmission to the intracranial contents. However, excessive helmet shell deformation at higher impact velocities may cause more severe secondary effect on the head, particularly the rear effect as described by Carroll and Soderstrom [9], in which the interior helmet shell hits the head directly. On the other hand, the top OA foam padding in Helmet 2 was preformed or compressed more significantly before the ballistic impact, as compared to the other foam paddings. This implies that the top foam reached the plateau region of its stress-strain curve before impact, thus decreasing its energy dissipative properties. Such phenomenon had been reported in Townsend and McCammond [52]'s experimental study which found that a skull with tightly padded helmet experienced higher stresses and strains than a skull with a loosely fitted helmet.

\section{Conclusion}

In this study, ballistic analysis using FEM had been carried out to evaluate the performance of the $\mathrm{ACH}$ as well as the effectiveness of its interior cushioning systems, in protect both 
military personnel and civilians from traumatic head injury. In previous work [48], it was shown that the FE results, in terms of the mechanical behavior of the assembly, extent of various forms of damage to the helmet laminate and the experimental parameters, correlated well with those obtained from ballistic experiments. Besides head kinematics, head's biomechanical metrics, such as skull von Mises stress, shear stresses, ICP, ventricular pressure and strains, which can neither be measured easily nor in vivo by experimental technique, were studied in the current work. Rarely reported case of top impact was also included in the analysis for a more complete and comprehensive understanding of head injuries in ballistic impact on helmet. Benchmarking with experimental ventricular and intracranial pressures showed that there is good agreement between the simulations and experiments.

The use of OA foams helped to reduce impact force and thus offered better protection from all various impact directions as the foams are more able to absorb energy, via plateau characteristic prior to foam densification, compared to the stiffer linear elastic front cushion of strap-netted helmet. Among all the impact directions, both the rear and lateral impacts resulted in more severe intracranial injuries while the top impact would give the least likelihood of any severe intracranial injury and skull fracture. This may imply that military personnel proning with his or her face down may prevent him or her from suffering non-penetrating TBI. Off-interior cushion impacts were also found to be at higher risk of intracranial injuries. As such, helmet liner with more number of padding inserts of smaller size would be more preferred as this configuration helps to dissipate the impact energy more effectively and minimize the blast-induced wavefocusing effect. This study highlights the need to explore various biomechanical metrics for brain injuries and provides some insights on future's helmet design against ballistic threats. 
(5736 words)

\section{Conflict of interest}

None.

\section{Acknowledgements}

This work was supported by the Defence Science Organization (DSO) of Singapore. Special thanks to their researchers for providing the Advanced Combat Helmets and various interior cushioning systems.

\section{References}

1. Aare M, Kleiven S (2007) Evaluation of head response to ballistic helmet impacts using the finite element method. International Journal of Impact Engineering 34:596-608. doi:10.1016/j.ijimpeng.2005.08.001

2. Abaqus (2013) Abaqus Analysis User's Manual. 6.13 edn. Dassault Systèmes Simulia Corp.,

3. Abu Talib AR, Abbud LH, Ali A, Mustapha F (2012) Ballistic impact performance of Kevlar29 and Al2O3 powder/epoxy targets under high velocity impact. Materials \& Design 35:12-19. doi:10.1016/j.matdes.2011.08.045

4. Al-Bsharat AS (2000) Computational analysis of brain injury. Wayne State University, Detroit

5. Alley Jr RH (1964) Head and neck injuries in high school football. JAMA 188:418-422

6. Bain AC, Meaney DF (2000) Tissue-level thresholds for axonal damage in an experimental model of central nervous system white matter injury. J Biomech Eng 122:615-622

7. Baumgartner D, Willinger R Finite element modelling of human head injuries caused by ballistic projectiles. In: NATO Research \& Technology Organisation (RTO) Specialist Meeting, Koblenz, Germany, 2003.

8. Beebe G, DeBakey M (1952) Battle casualties: incidence, mortality, and logistic considerations. In: Death From Wounding. Springfield, IL: Charles C Thomas, pp 74147

9. Carroll AW, Soderstrom CA (1978) A new nonpenetrating ballistic injury. Ann Surg 188:753757

10. Deck C, Willinger R (2008) Improved head injury criteria based on head FE model. International Journal of Crashworthiness 13:667-678 
11. Ewing CL, Irving AM (1969) Evaluation of head protection in aircraft. Aerosp Med 40:596599

12. Feli S, Yas MH, Asgari MR (2011) An analytical model for perforation of ceramic/multilayered planar woven fabric targets by blunt projectiles. Composite Structures 93:548556. doi:10.1016/j.compstruct.2010.08.025

13. Galbraith JA, Thibault LE, Matteson DR (1993) Mechanical and electrical responses of the squid giant axon to simple elongation. J Biomech Eng 115:13-22

14. Ganpule S, Gu L, Chandra N Modeling shock response of helmeted head using fluid structure interaction. In: 16th US National Congress of Theoretical and Applied Mechanics, Pennsylvania, USA, 2010. pp 1-3

15. Goel R (2010) Study of an advanced helmet liner concept to reduce TBI: Experiments \& simulation using sandwich structures. Massachusetts Institute of Technology (MIT), Berkeley

16. Goldsmith W, Khalil TB Effect of a protective device in the reduction of head injury. In: Int. Conf. on Biokinetics of Impacts, Amsterdam, the Netherlands, 1973.

17. Grellmann W, Berghaus A, Haberland EJ, Jamali Y, Holweg K, Reincke K, Bierögel C (2006) Determination of strength and deformation behavior of human cartilage for the definition of significant parameters. Journal of Biomedical Materials Research Part A 78A:168-174. doi:10.1002/jbm.a.30625

18. Ha-Minh C, Boussu F, Kanit T, Crépin D, Imad A (2011) Analysis on failure mechanisms of an interlock woven fabric under ballistic impact. Engineering Failure Analysis 18:21792187. doi:10.1016/j.engfailanal.2011.07.011

19. Ha-Minh C, Kanit T, Boussu F, Imad A (2011) Numerical multi-scale modeling for textile woven fabric against ballistic impact. Computational Materials Science 50:2172-2184. doi:10.1016/j.commatsci.2011.02.029

20. Horgan TJ, Gilchrist MD (2004) Influence of FE model variability in predicting brain motion and intracranial pressure changes in head impact simulations. International Journal of Crashworthiness 9:401-408

21. Johnson GR, Cook WH A constitutive model and data for metals subjected to large strains, high strain rates and high temperature. In: the 7th International Symposium on Ballistics, 1983. pp 541-547

22. Khalil TB (1973) Impact on a model head-helmet system. University of California, Berkeley

23. Khalil TB, Goldsmith W, Sackman JL (1974) Impact on a model head-helmet system. International Journal of Mechanical Sciences 16:609-625. doi:10.1016/00207403(74)90061-7

24. Kleiven S (2006) Evaluation of head injury criteria using a finite element model validated against experiments on localized brain motion, intracerebral acceleration, and intracranial pressure. International Journal of Crashworthiness 11:65-79

25. Kleiven S Parametric studies of the ballistic helmet design. In: 9th Symposium on Plasticity and Impact Mechanics (IMPLAST), Bochum, Germany, 2007. pp 127-134

26. Kleiven S, Hardy WN Correlation of an FE model of the human head with local brain motion-consequences for injury prediction. In: 46th Stapp Car Crash Conference, Ponte Vedra, USA, Nov 2002. Society of Automotive Engineers (SAE), SAE Paper No. 200222-0007, pp 123-144. doi:2002-22-0007 [pii] 
27. Lamy M, Baumgartner D, Yoganandan N, Stemper B, Willinger R (2013) Experimentally validated three-dimensional finite element model of the rat for mild traumatic brain injury. Med Bio Eng Comput 51:353-365. doi:10.1007/s11517-012-1004-7

28. Lee HP, Gong SW (2010) Finite element analysis for the evaluation of protective functions of helmets against ballistic impact. Computer Methods in Biomechanics and Biomedical Engineering 13:537-550. doi:10.1080/10255840903337848

29. Long J, Yang J, Lei Z, Liang D (2013) Simulation-based assessment for construction helmets. Computer Methods in Biomechanics and Biomedical Engineering 18:24-37. doi:10.1080/10255842.2013.774382

30. Mamivand M, Liaghat GH (2010) A model for ballistic impact on multi-layer fabric targets. International Journal of Impact Engineering 37:806-812. doi:10.1016/j.ijimpeng.2010.01.003

31. Mathers CD, Lopez AD, Murray CJL (2006) The burden of disease and mortality by condition: Data, methods and results for 2001. In: Lopez A, Mathers C, Ezzati M, Jamison DT, Murray CJL (eds) Global Burden of Disease and Risk Factors. 1st edn. The International Bank for Reconstruction and Development/ The World Bank Group, Washington, D.C, pp 45-240

32. McElhaney JH, Fogle JL, Melvin JW, Haynes RR, Roberts VL, Alem NM (1970) Mechanical properties on cranial bone. J Biomech 3:495-511

33. Miller RT, Margulies SS, Leoni M, Nonaka M, Chen X, Smith DH, Meaney DF Finite element modeling approaches for predicting injury in an experimental model of severe diffuse axonal injury. In: 42nd Stapp Car Crash Conference, Tempe, USA, 1998. Society of Automotive Engineers (SAE), SAE Paper No. 983154, pp 155-166

34. Mills NJ (2007) Finite element modelling of foam deformation. In: Polymer Foams Handbook: Engineering and Biomechanics Applications and Design Guide. ButterworthHeinemann, Oxford, pp 115-145

35. Morrison B, 3rd, Cater HL, Wang CC, Thomas FC, Hung CT, Ateshian GA, Sundstrom LE (2003) A tissue level tolerance criterion for living brain developed with an in vitro model of traumatic mechanical loading. Stapp Car Crash J 47:93-105

36. Moss WC, King MJ, Blackman EG (2009) Skull flexure from blast waves: a mechanism for brain injury with implications for helmet design. Phys Rev Lett 103:108702

37. National Institute of Justice (NIJ) Standard, NILECJ-STD-0106.00: Ballistic Helmets (1975). Washington, DC, US

38. Nyein MK, Jason AM, Yu L, Pita CM, Joannopoulos JD, Moore DF, Radovitzky RA (2010) In silico investigation of intracranial blast mitigation with relevance to military traumatic brain injury. Proceedings of the National Academy of Sciences. doi:10.1073/pnas.1014786107

39. Patrick LM Head Impact Protection. In: Caveness WF, Walker AE (eds) Head Injury Conference, 1966. Lippincott, Philadelphia, pp 41-48

40. Payan Y, Bettega G, Raphael B (1998) A biomechanical model of the human tongue and its clinical implication. Paper presented at the MICCAI'98, LNCS 1496,

41. Pintar FA, Philippens MMGM, Zhang J, Yoganandan N (2013) Methodology to determine skull bone and brain responses from ballistic helmet-to-head contact loading using experiments and finite element analysis. Medical Engineering \& Physics 0. In Press, Corrected Proof, Available online $20 \quad$ June 2013. doi:http://dx.doi.org/10.1016/j.medengphy.2013.04.015 
42. Rao MP, Duan Y, Keefe M, Powers BM, Bogetti TA (2009) Modeling the effects of yarn material properties and friction on the ballistic impact of a plain-weave fabric. Composite Structures 89:556-566. doi:10.1016/j.compstruct.2008.11.012

43. Rayne JM, Maslen KR (1969) Factors in the design of protective helmets. Aerospace Medicine 40:631-637

44. Salimi Jazi M, Rezaei A, Karami G, Azarmi F, Ziejewski M (2014) A computational study of influence of helmet padding materials on the human brain under ballistic impacts. Computer Methods in Biomechanics and Biomedical Engineering 17:1368-1382. doi:10.1080/10255842.2012.748755

45. Sarron J-C, Caillou J-P, Da Cunha J, Allain J-C, Trameçon, Alain (2000) Consequences of Nonpenetrating Projectile Impact on a Protected Head: Study of Rear Effects of Protections. Journal of Trauma- Injury, Infection, and Critical Care 49:923-929

46. Sarron J-C, Dannawi M, Faure A, Caillou J-P, Da Cunha J, Robert R (2004) Dynamic Effects of a $9 \mathrm{~mm}$ Missile on Cadaveric Skull Protected by Aramid, Polyethylene or Aluminum Plate: An Experimental Study. Journal of Trauma- Injury, Infection, and Critical Care 57:236-243

47. Shreiber DI, Bain AC, Meaney DF In vivo thresholds for mechanical injury to the bloodbrain barrier. In: 41st Stapp Car Crash Conference, Orlando, USA, 1997. Society of Automotive Engineers (SAE), SAE Paper No. 973335, pp 277-291

48. Tan LB, Tse KM, Lee HP, Tan VBC, Lim SP (2012) Performance of an advanced combat helmet with different interior cushioning systems in ballistic impact: Experiments and finite element simulations. International Journal of Impact Engineering 50:99-112. doi:10.1016/j.ijimpeng.2012.06.003

49. Tan VBC, Ching TW (2006) Computational simulation of fabric armour subjected to ballistic impacts. International Journal of Impact Engineering 32:1737-1751. doi:10.1016/j.ijimpeng.2005.05.006

50. Tanne K, Hiraga J, Kakiuchi K, Yamagata Y, Sakuda M (1989) Biomechanical effect of anteriorly directed extraoral forces on the craniofacial complex: A study using the finite element method. American Journal of Orthodontics and Dentofacial Orthopedics 95:200207. doi:Doi: 10.1016/0889-5406(89)90050-4

51. Tham CY, Tan VBC, Lee HP (2008) Ballistic impact of a KEVLAR® helmet: Experiment and simulations. International Journal of Impact Engineering 35:304-318. doi:10.1016/j.ijimpeng.2007.03.008

52. Townsend MA, McCammond D, Lie G (1975) Response of human and anthropometric model skulls to impact loading. Med \& biol Engng 13:405-413. doi:10.1007/BF02477112

53. Tse KM, Tan LB, Lee SJ, Lim SP, Lee HP (2014) Development and validation of two subject-specific finite element models of human head against three cadaveric experiments. International Journal for Numerical Methods in Biomedical Engineering 30:397-415. doi:10.1002/cnm.2609

54. Van Hoof J, Cronin DS, Worswick MJ, Williams KV, Nandlall D Numerical head and composite helmet models to predict blunt trauma. In: 19th International Symposium on Ballistics, Interlaken, Switzerland., 7-11 May 20012001.

55. Van Hoof J, Deutekom MJ, Worswick MJ, Bolduc M Experimental and numerical analysis of the ballistic response of composite helmet materials. In: 18th International Symposium on Ballistics, San Antonio, TX, USA, 15-19 November 19991999. 
56. Wang F, Lee H, Lu C (2007) Effects of head size and morphology on dynamic responses to impact loading. Med Bio Eng Comput 45:747-757. doi:10.1007/s11517-007-0198-6

57. Ward CC, Chan M, Nahum AM Intracranial pressure-a brain injury criterion. In: 24th Stapp Car Crash Conference, Warrendale, USA, 1980. Society of Automotive Engineers (SAE), SAE Paper No. 801304., pp 347-360

58. Westreich RW, Courtland HW, Nasser P, Jepsen K, Lawson W (2007) Defining nasal cartilage elasticity: biomechanical testing of the tripod theory based on a cantilevered model. Arch Facial Plast Surg 9:264-270. doi:10.1001/archfaci.9.4.264

59. Willinger R, Kang HS, Diaw B (1999) Three-dimensional human head finite-element model validation against two experimental impacts. Annals of Biomedical Engineering 27:403410. doi: $10.1114 / 1.165$

60. Yang J, Dai J (2010) Simulation-based assessment of rear effect to ballistic helmet impact. Computer-Aided Design and Applications 7:59-73. doi:citeulike-article-id:9593024

61. Zhang L, Yang KH, King AI (2001) Comparison of brain responses between frontal and lateral impacts by finite element modeling. J Neurotrauma 18:21-30. doi:10.1089/089771501750055749 [doi]

62. Zhang L, Yang KH, King AI (2004) A proposed injury threshold for mild traumatic brain injury. Journal of Biomechanical Engineering 126:226-236. doi:10.1115/1.1691446

\section{Author's Biography:}

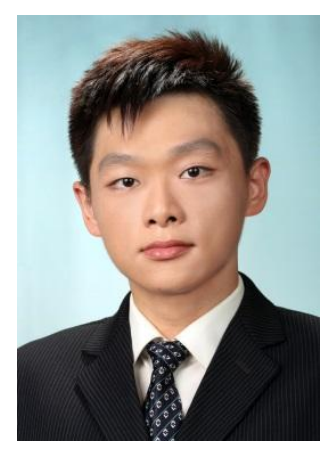

Tse KM was a postdoctoral researcher in National University of Singapore (Singapore) before he joined University of Melbourne (Australia), whose expertise is in finite element modeling and simulation. He has worked on various defence projects and his research focuses on computational biomechanics. 


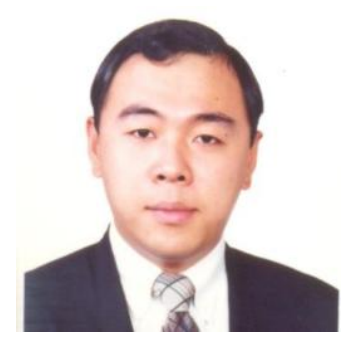

Tan LB is a postdoctoral researcher in National University of Singapore (Singapore). His specialty is finite element modeling and simulation. He has worked on numerous projects in various fields from biomechanics to acoustics.

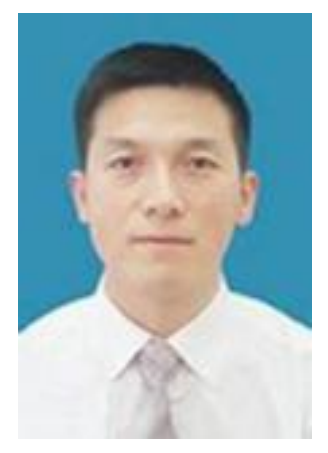

Prof. Yang B is the Vice Dean and Associate Professor in Automobile and Transportation Engineering, Nanjing Forestry University (China). His research focuses on transportation safety and pedestrian protection.

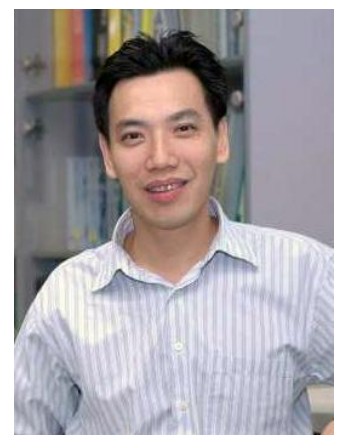


Prof. Tan VBC is the Deputy Head (Admin) for Department of Mechanical Engineering, National University of Singapore (Singapore). His research interest lies in impact mechanics (composite) and computational mechanics (multiscale modeling).

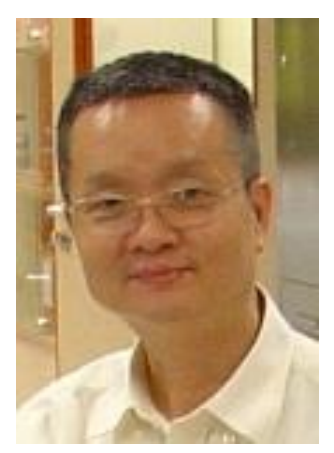

Prof. Lee HP is currently the Deputy Head (Research) for Department of Mechanical Engineering, National University of Singapore (Singapore). His recent notable works focus on mechanics in medicine, mechanics of biofouling and acoustics.

\section{Figure Caption}

Figure 1: (a) The mid-sagittal view of the helmet-strap-netting-FEHM assembly on the top while the preformed strap-netting system on the bottom; (b) The helmet, the strap-netting system and the OA foam padding system before the fitting step; (c) mid-sagittal view of the helmet-foampadding-FEHM assembly on the top while the preformed OA foam-padding system on the bottom. 
Figure 2: (a) The surface node set comprising the top and rear portion of the head which is usually covered by the helmet. (b) Head contact force history plots during the helmet fitting step.

Figure 3: The maximum von Mises stress experienced by the skull in NIJ simulations.

Figure 4: Maximum von Mises stress experienced by the skull.

Figure 5: The sagittal views of maximum and minimum ICP experienced by the brain tissues in NIJ simulations.

Figure 6: The maximum or minimum ventricular pressure in NIJ simulations.

Figure 7: (a) Maximum ICP and (b) maximum ventricular pressure for various impact orientation and helmet liner configuration.

Figure 8: The maximum principle strains (left) and maximum shear strains experienced by the white matter in NIJ simulations. Note: RA represents right-anterior view while RP represents right-posterior view.

Figure 9: The maximum principle strains (left) and maximum shear strains experienced by the brainstem in NIJ simulations. Note: R represents right view while L represents left view. 
Figure 10: Maximum principal and shear strains experienced by (a) white matter and (b) brainstem for various impact orientation and helmet liner configuration.

Figure 11: (A) Peak acceleration and (B) HIC Scores at the C.G. of the head for various impact orientation and helmet liner configuration.

a

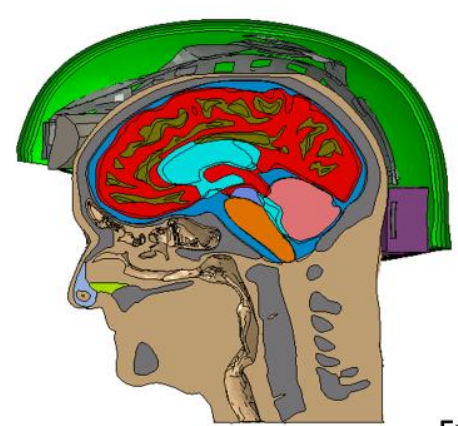

b
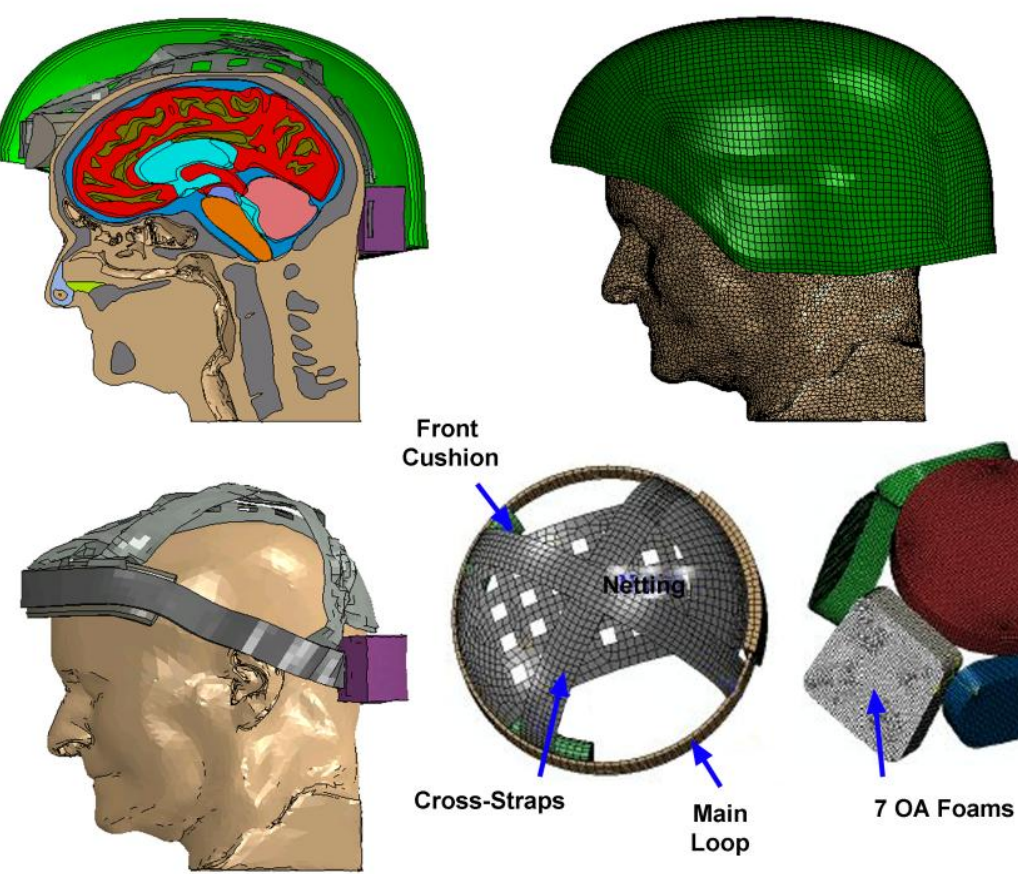

Front
Cushion

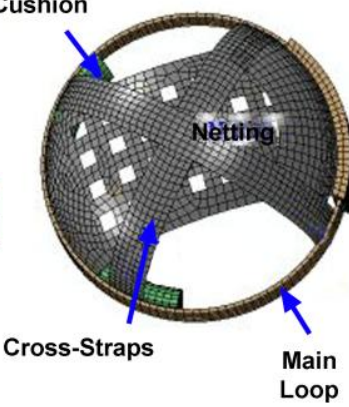

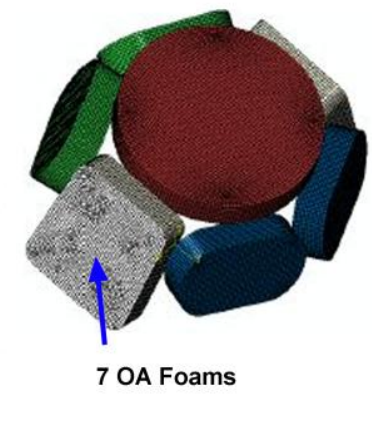

c

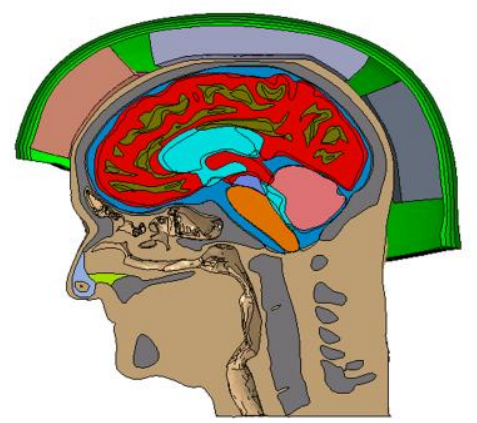

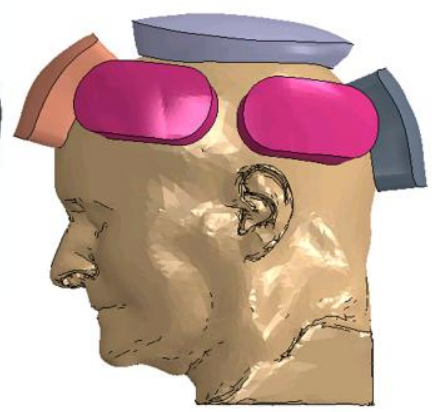




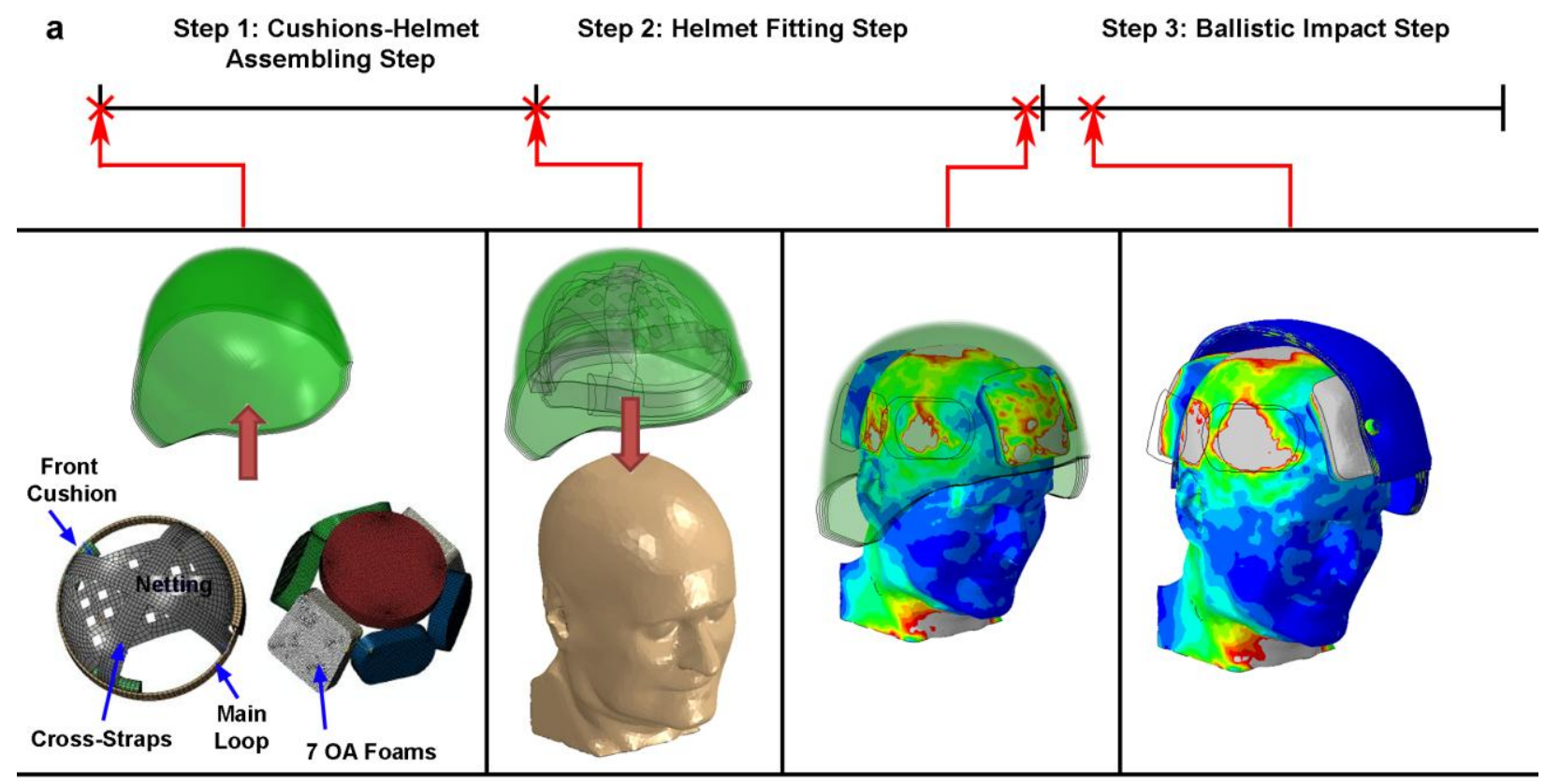

b Contact Force

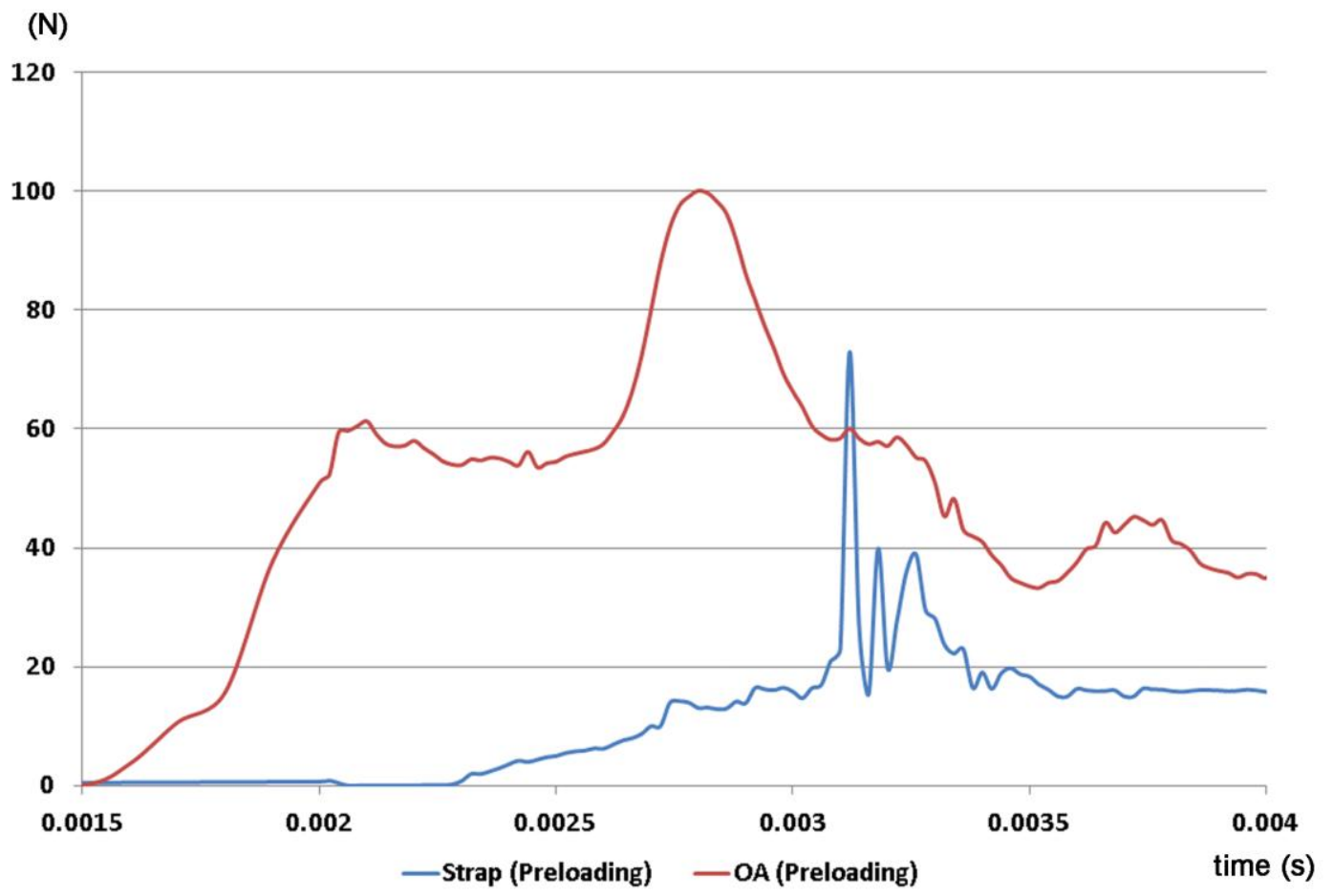


a1

Frontal Impact

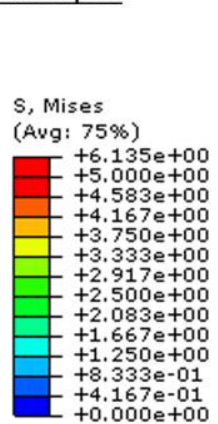

b1

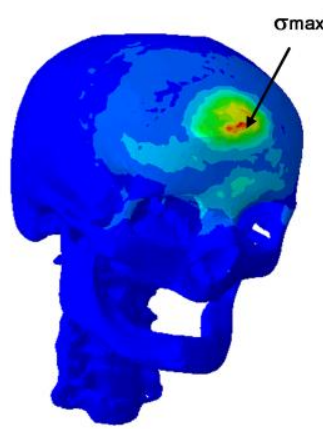

Lateral Impact
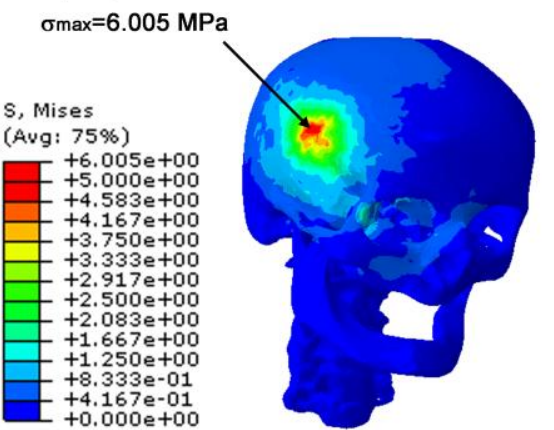

c1

Rear Impact
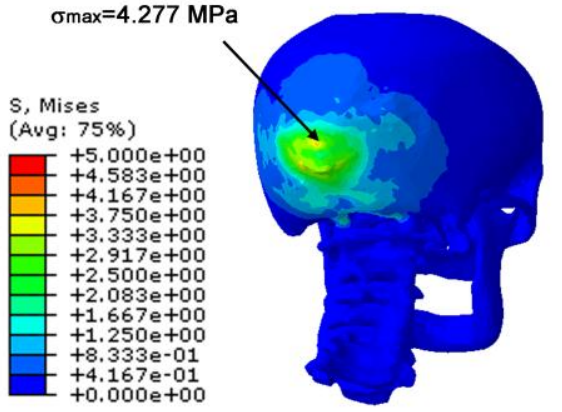

Top Impact
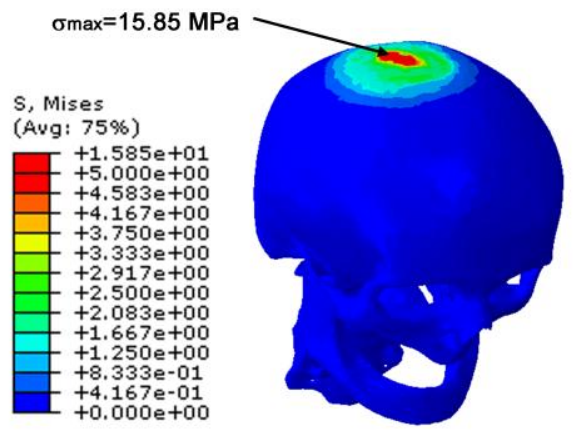

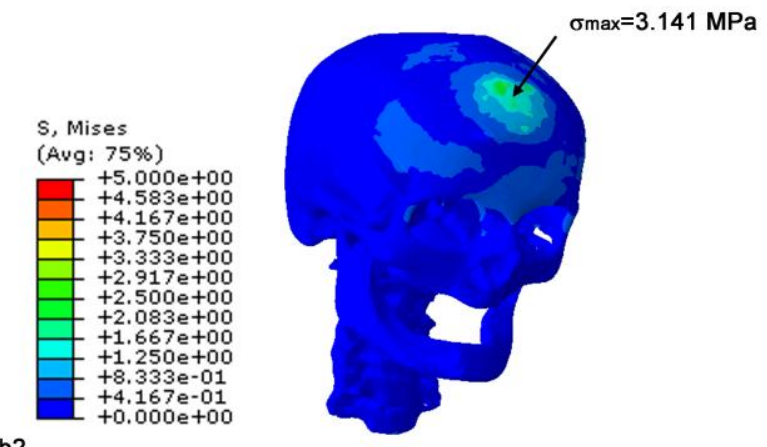

b2

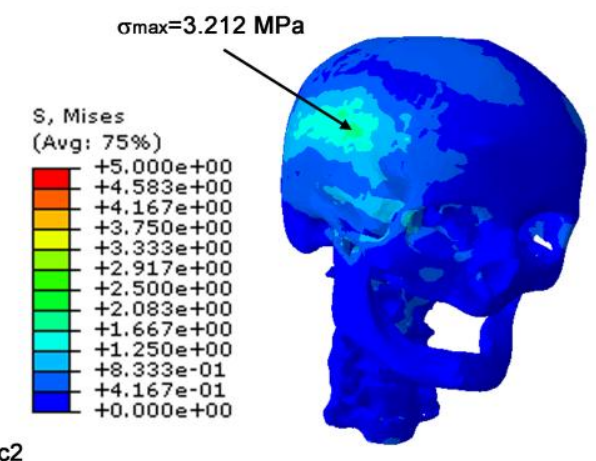

c2

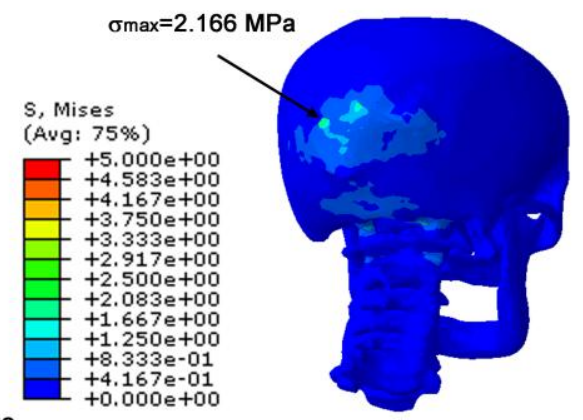

d2

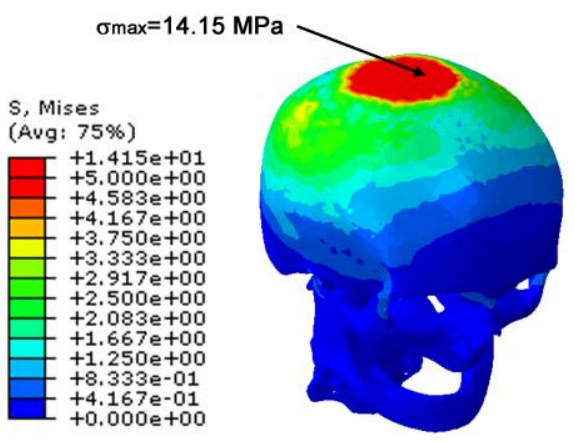




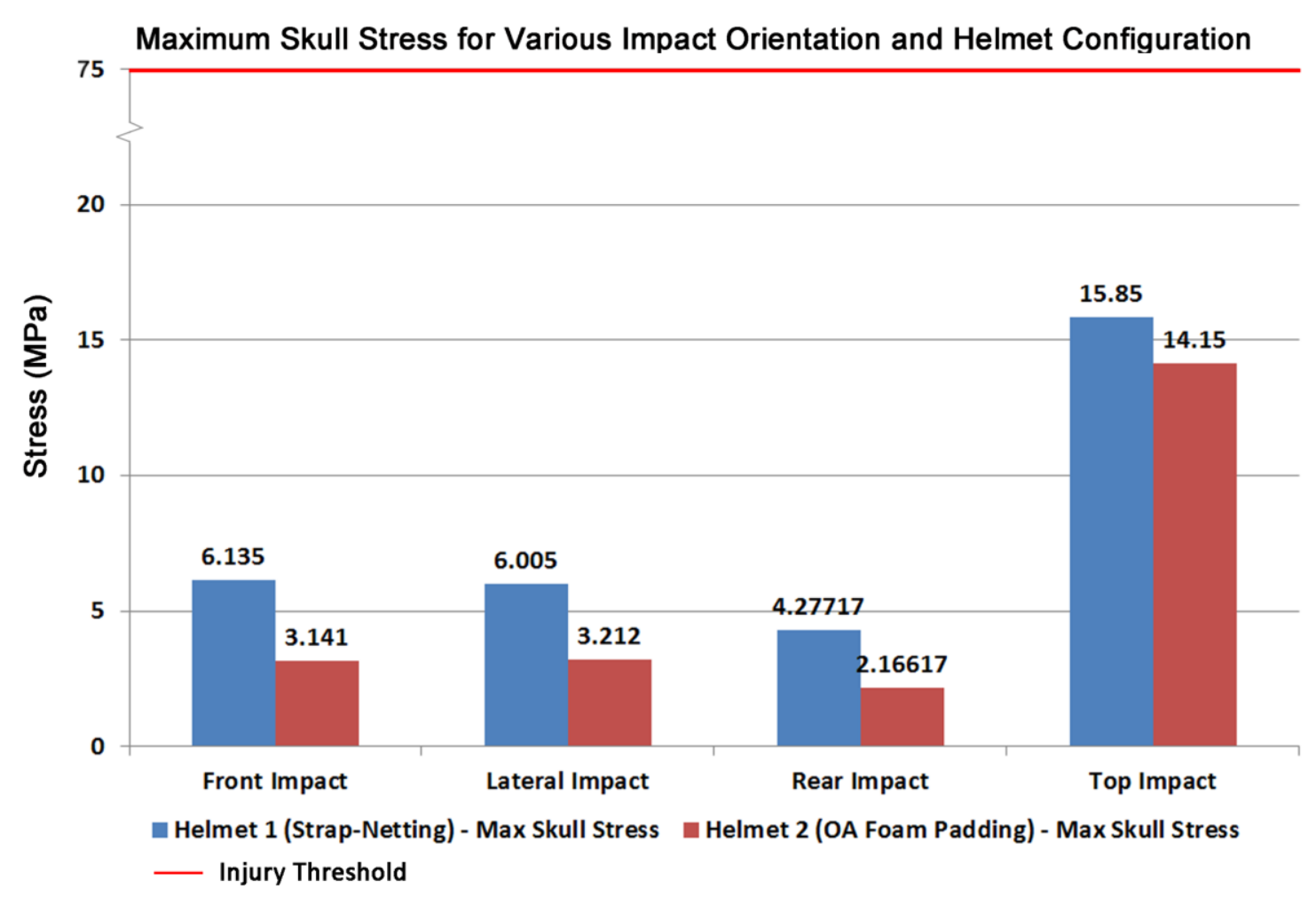




\title{
Helmet 1 (Strap-Netting)
}

a1

Frontal Impact

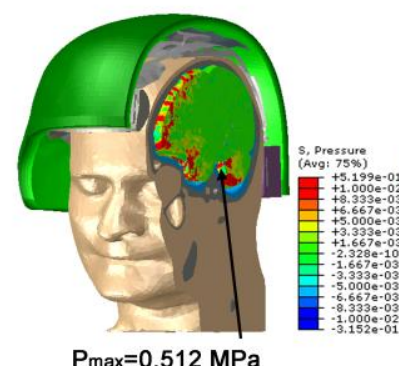

b1

$\underline{\text { Lateral Impact }}$

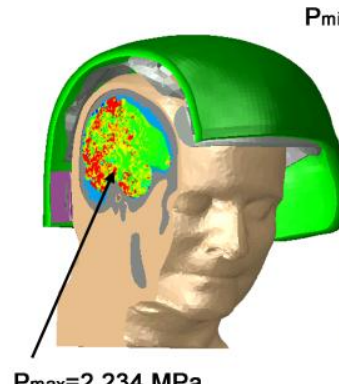

$\mathrm{P}_{\max }=2.234 \mathrm{MPa}$

c1

Rear Impact

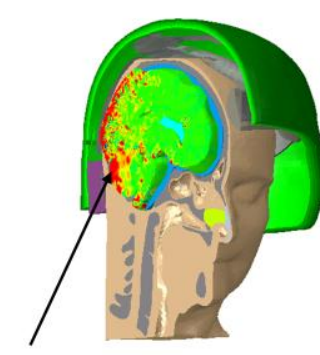

$P_{\max }=0.831 \mathrm{MPa}$

d1

Top Impact

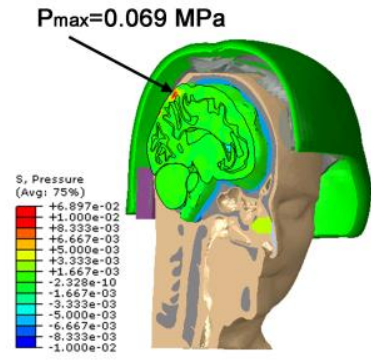

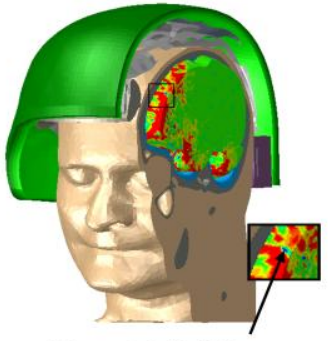

$P_{\min }=-0.315 \mathrm{MPa}$ a2

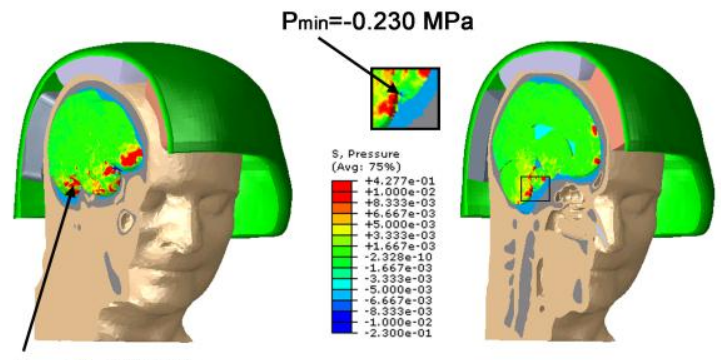

b2

\section{$\mathrm{P}_{\max }=0.428 \mathrm{MPa}$}

Helmet 2 (OA Foam Padding)

\author{
che
}


a1

Frontal Impact

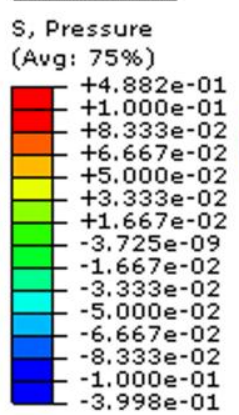

b1

Lateral Impact

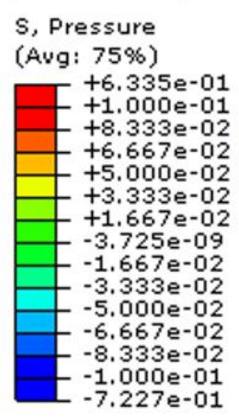

c1

Rear Impact

S, Pressure
(Avg: 75\%)

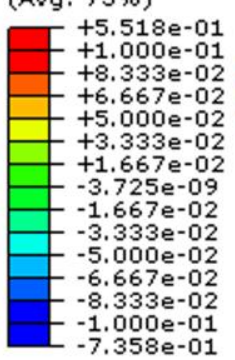

d1

Top Impact

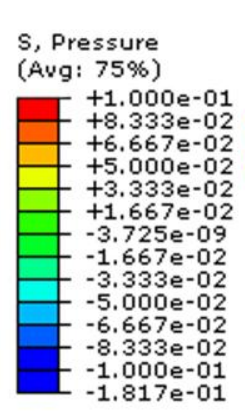

Helmet 1 (Strap-Netting)

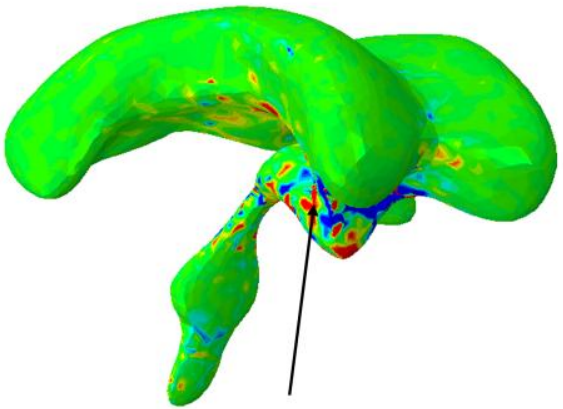

$P_{\max }=0.488 \mathrm{MPa}$

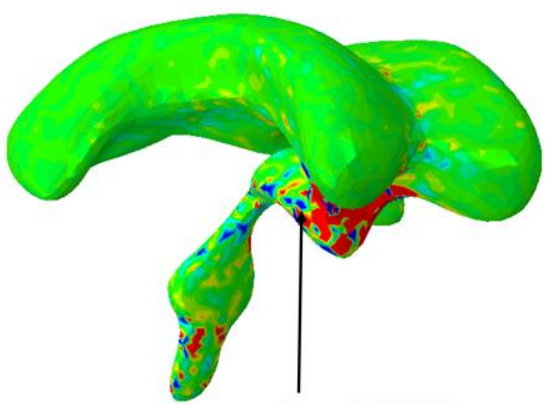

$P_{\min }=-0.723 \mathrm{MPa}$

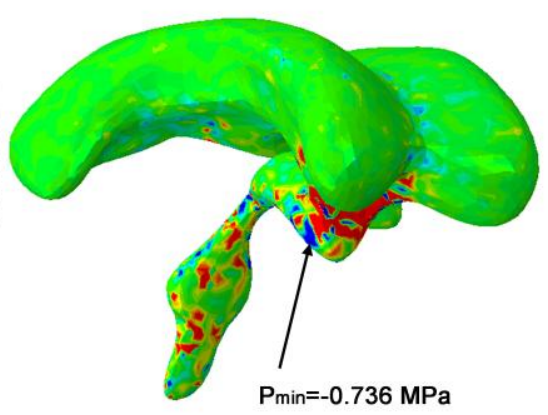

$P_{\min }=-0.736 \mathrm{MPa}$

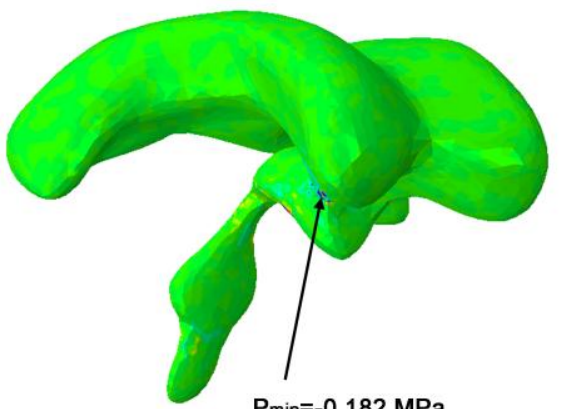

a2

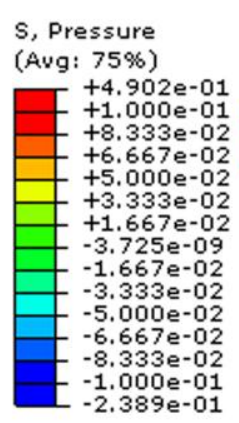

b2

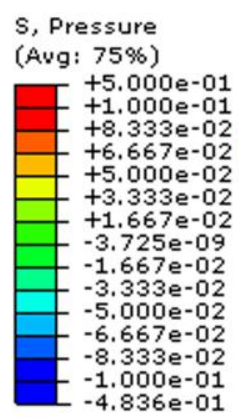

c2
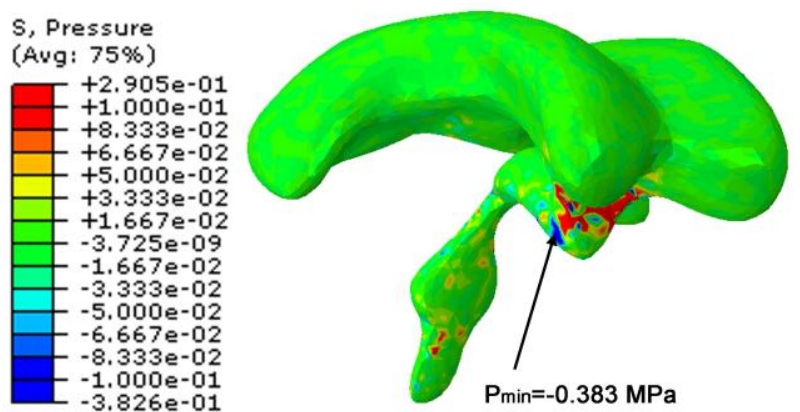

d2
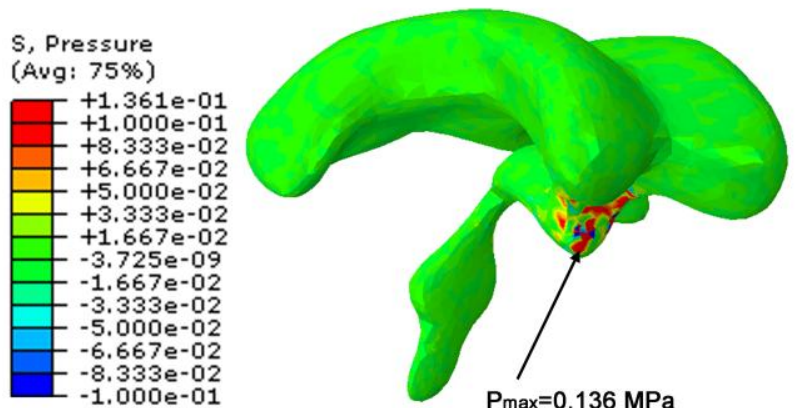

Helmet 2 (OA Foam Padding)

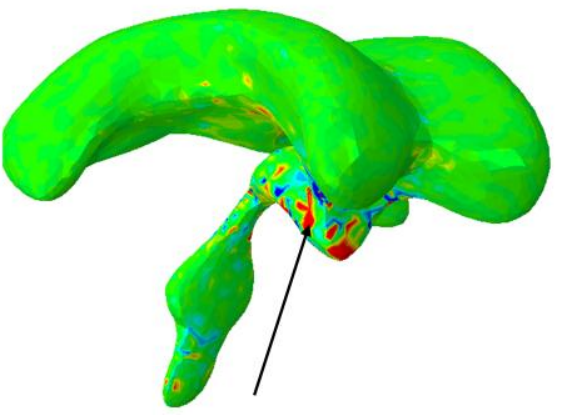

$P_{\max }=0.490 \mathrm{MPa}$

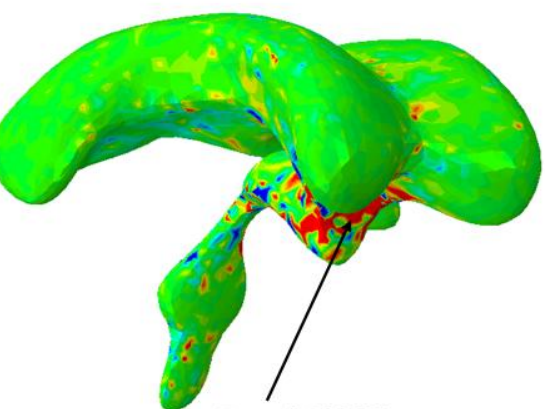

$\mathrm{P}_{\max }=0.500 \mathrm{MPa}$

$P_{\min }=-0.383 \mathrm{MPa}$

$\mathrm{P}_{\max }=0.136 \mathrm{MPa}$ 


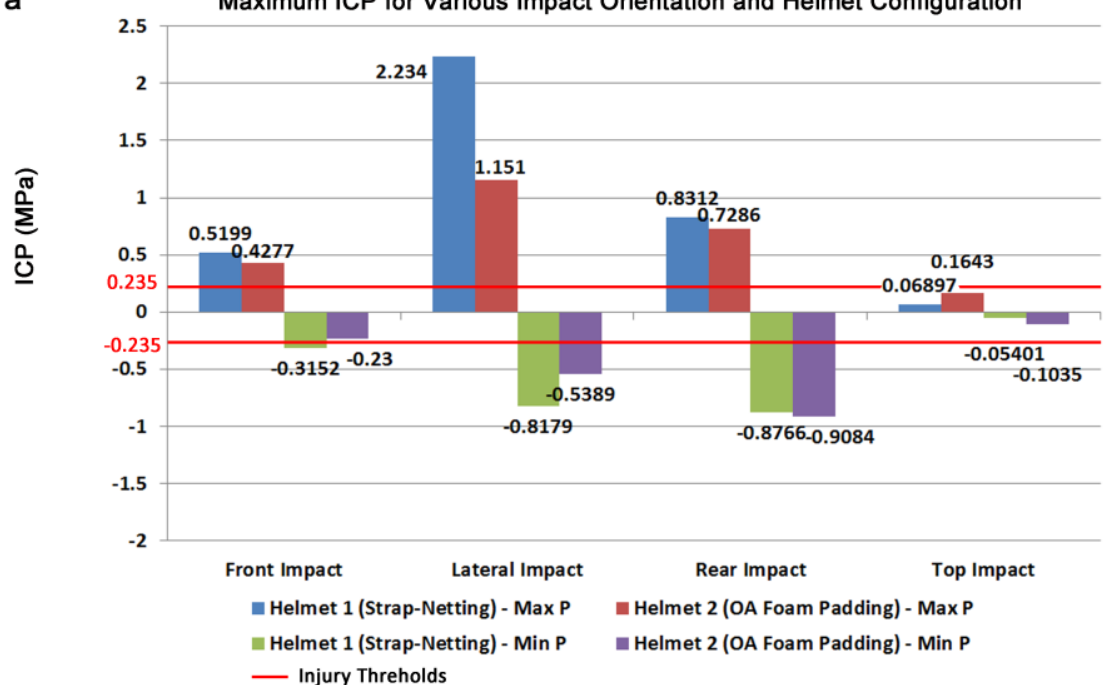

b Maximum Ventricular Pressure for Various Impact Orientation and Helmet Configuration

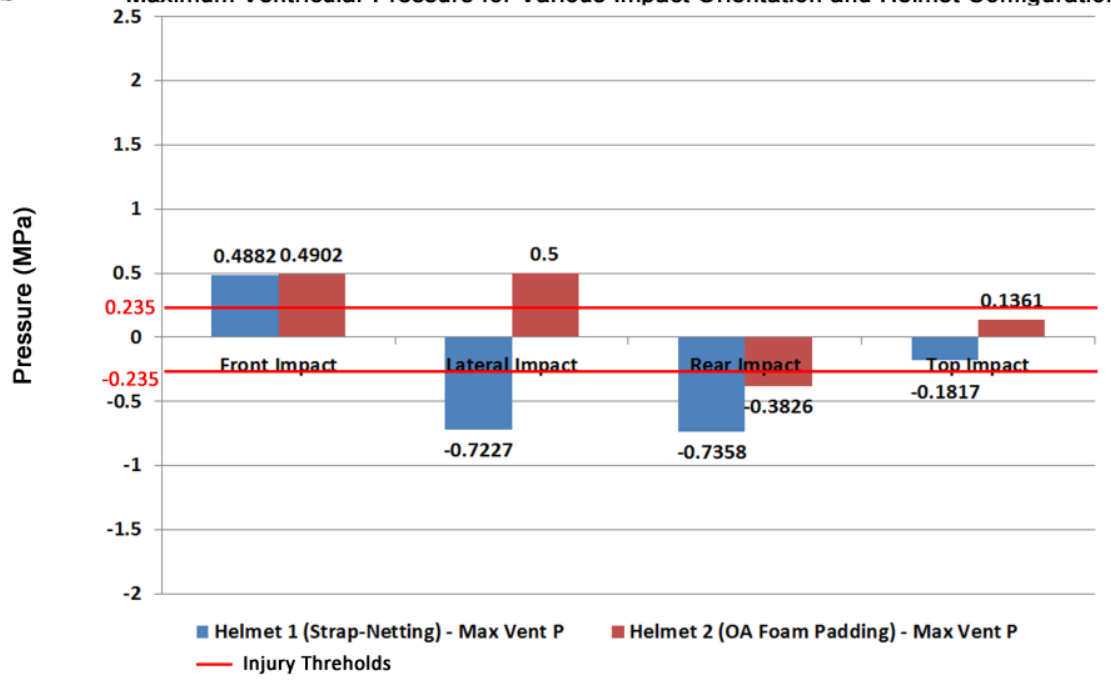


Helmet 1 (Strap-Netting)

a1

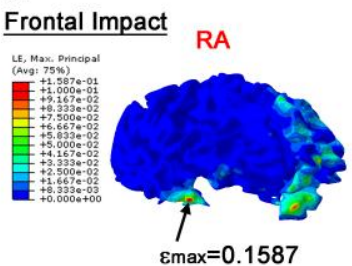

b1

Lateral Impact

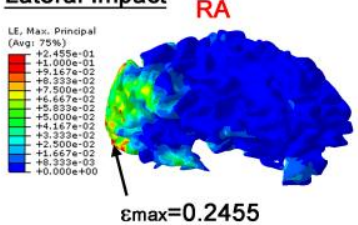

c1
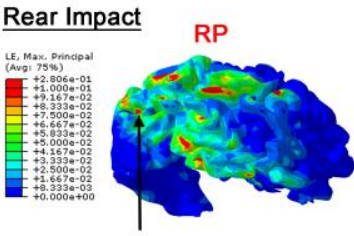

$\varepsilon \max =0.2806$

d1

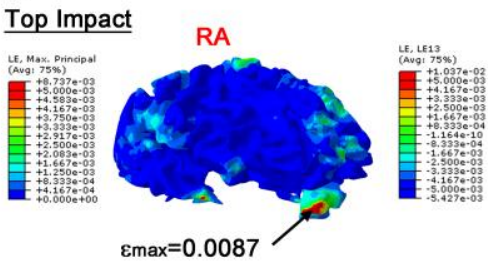

a2

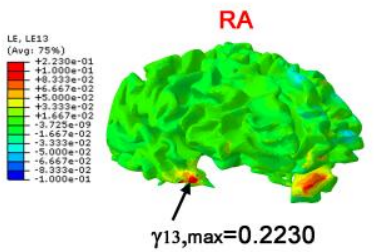

RA

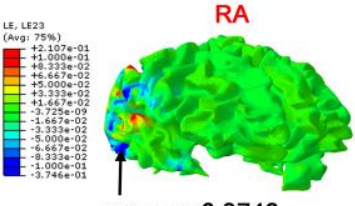

$\gamma 23, \max =-0.3746$
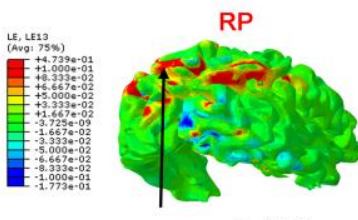

$\gamma 13$,max $=0.4739$

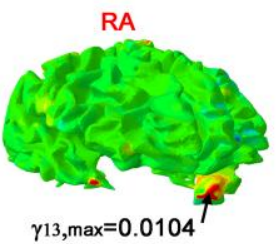

b2

d2
Helmet 2 (OA Foam Padding)
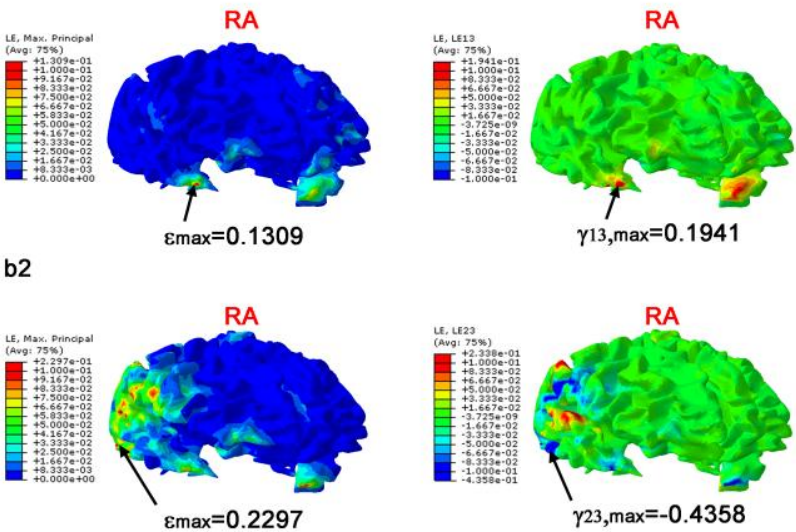

c2

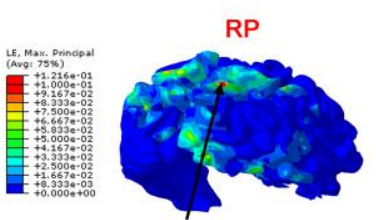

$\varepsilon \max =0.1216$
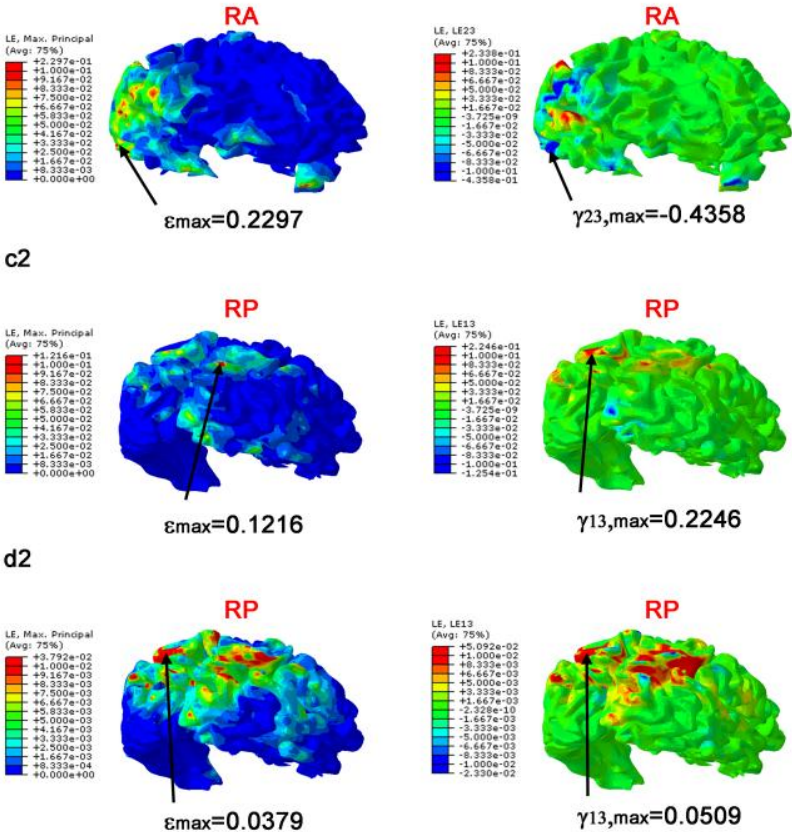
Helmet 1 (Strap-Netting)

a1

Frontal Impact $\quad \mathrm{R}$

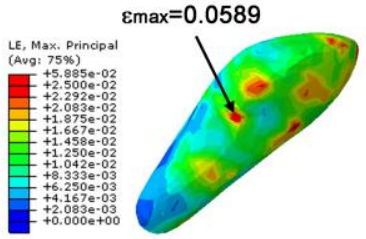

b1

Lateral Impact R

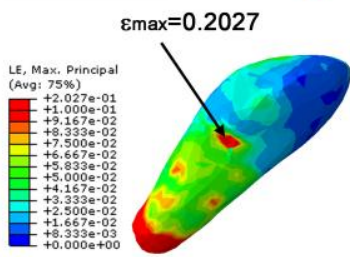

c1

Rear Impact R

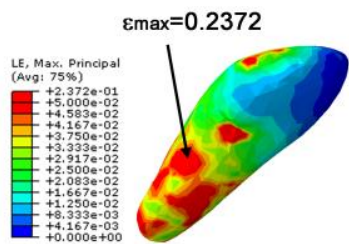

d1

Top Impact L

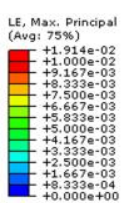

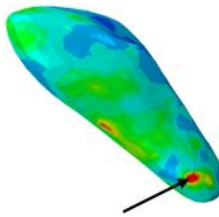

$\varepsilon \max =0.0191$
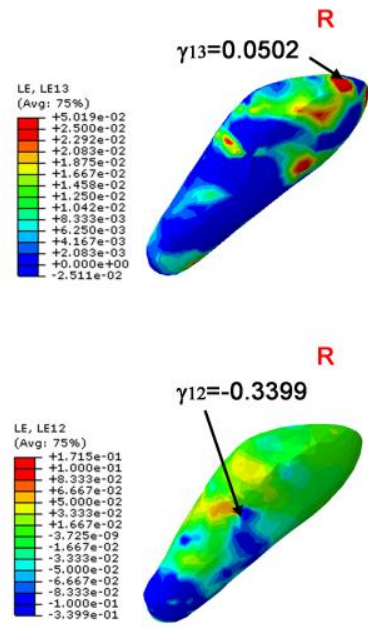

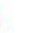

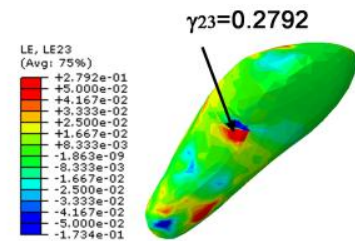

L

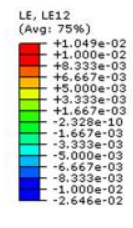

a2

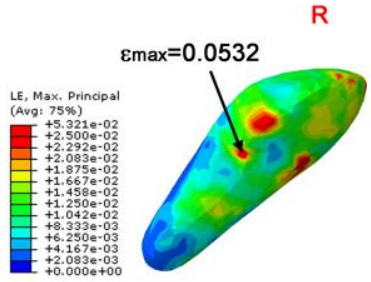

b2

$\mathrm{R}$

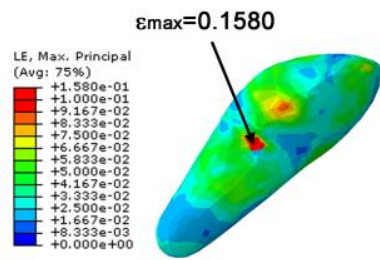

c2

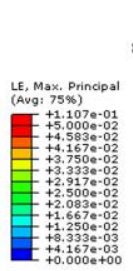

d2

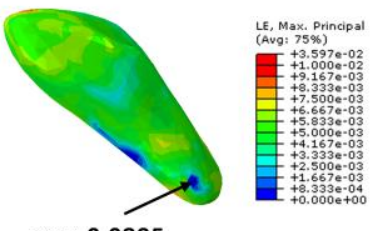

$\mathrm{R}$

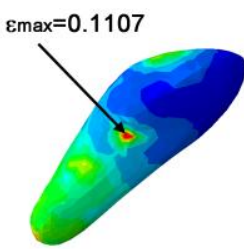

L
Helmet 2 (OA Foam Padding)
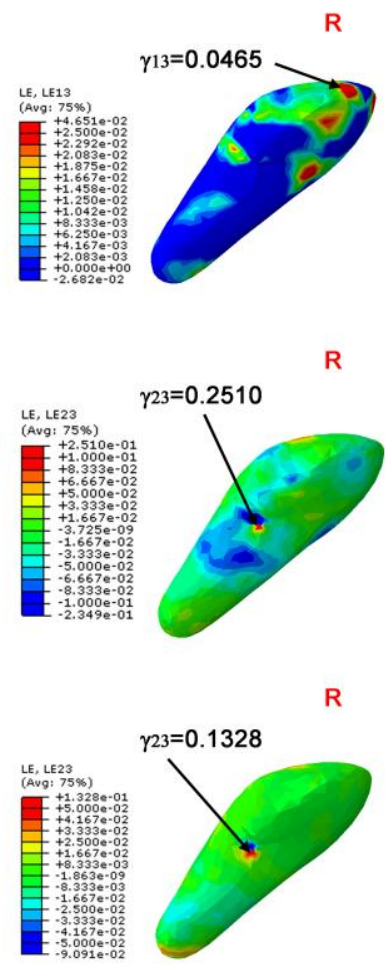

L

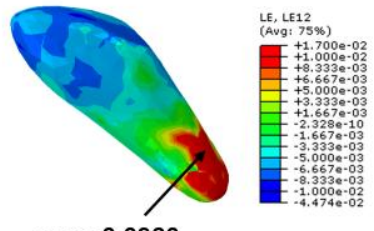

$\varepsilon_{\max }=0.0360$

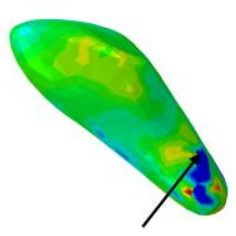

$\gamma_{12}=-0.0447$ 


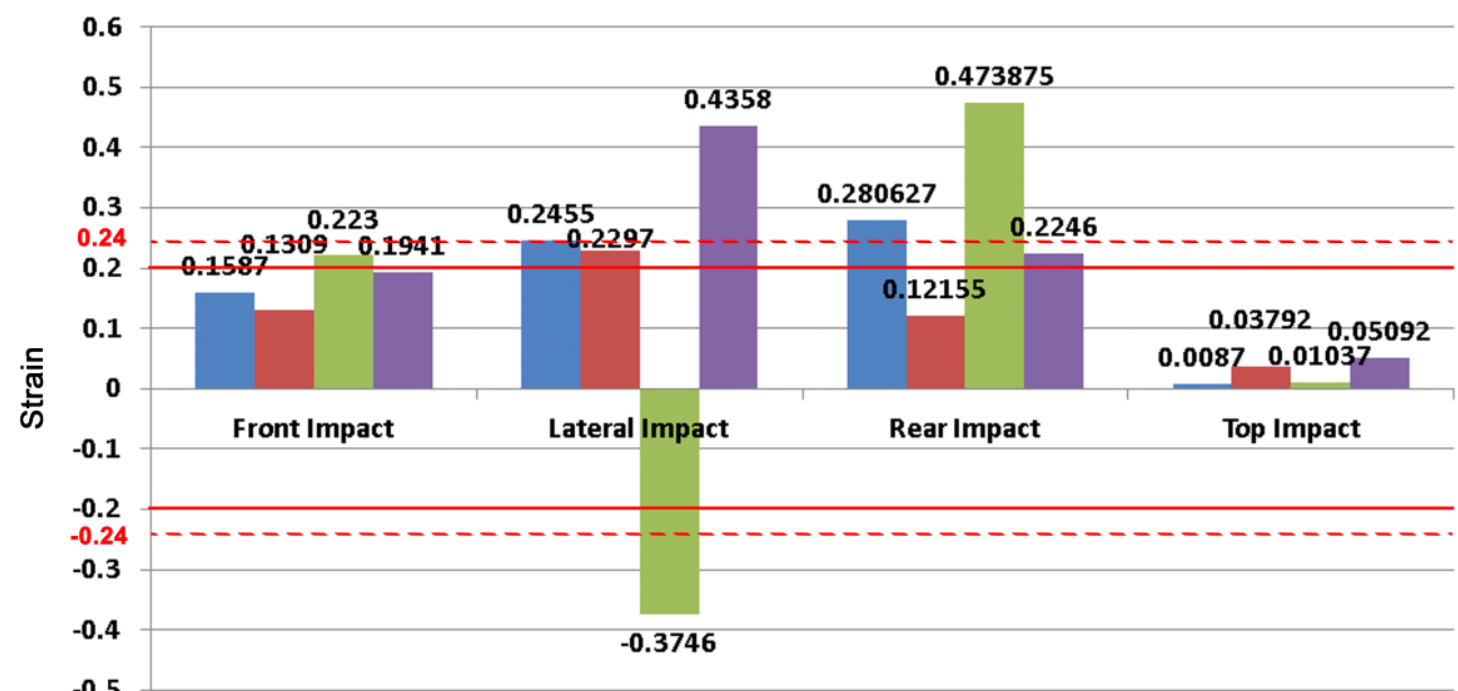

$-0.5$
- Helmet 1 (Strap-Netting) - Max WM Principal Strain
- Helmet 2 (OA Foam Padding) - Max WM Principal Strain
nelmet 1 (Strap-Netting) - Max WM Shear Strain
- Helmet 2 (OA Foam Padding) - Max WM Shear Strain
— Injury Thresholds for Principal Strain
- - - Injury Thresholds for Shear Strain

Maximum Brainstem Strains for Various Impact Orientation and Helmet Configuration

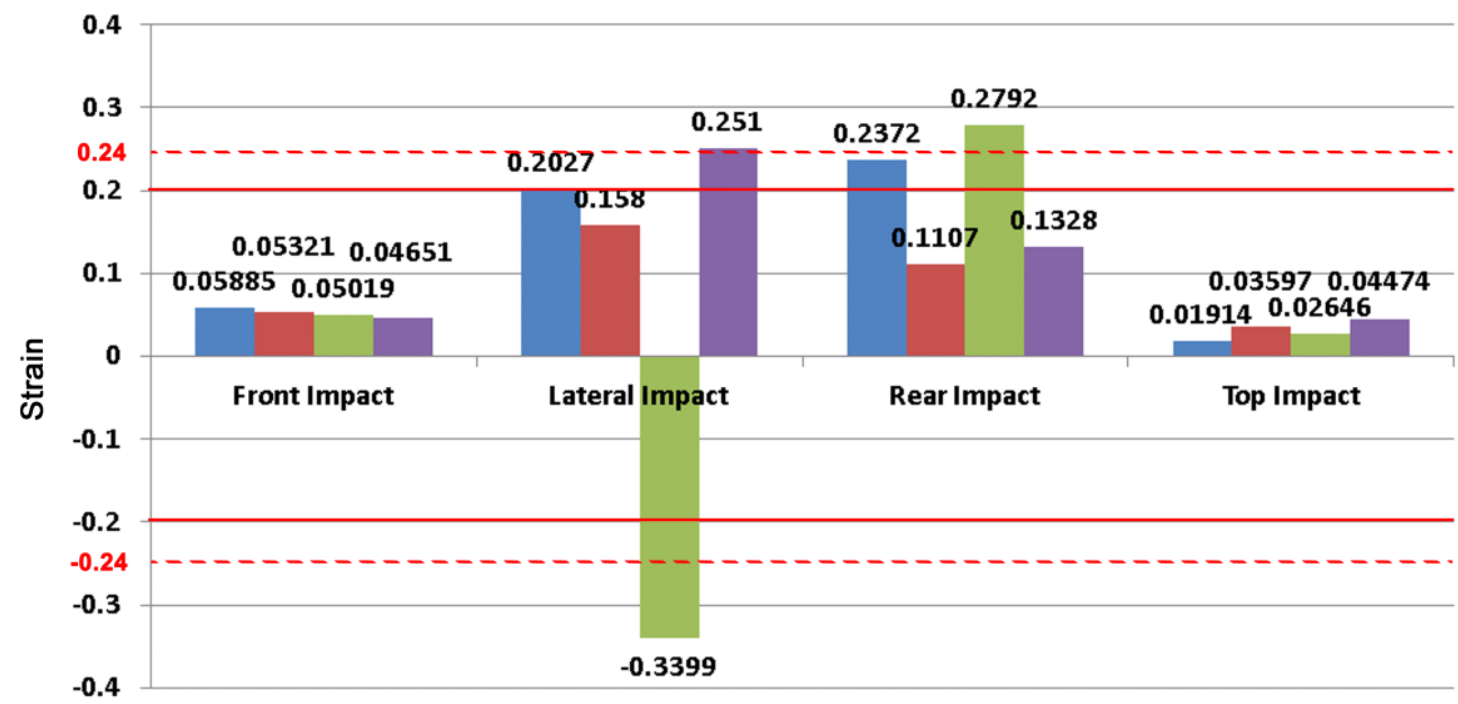

- Helmet 1 (Strap-Netting) - Max BS Principal Strain

- Helmet 2 (OA Foam Padding) - Max BS Principal Strain

- Helmet 1 (Strap-Netting) - Max BS Shear Strain

- Helmet 2 (OA Foam Padding) - Max BS Shear Strain

— Injury Thresholds for Principal Strain

-- - Injury Thresholds for Shear Strain 
a Peak Acceleration of Head C.G. for Various Impact Orientation and Helmet Configuration

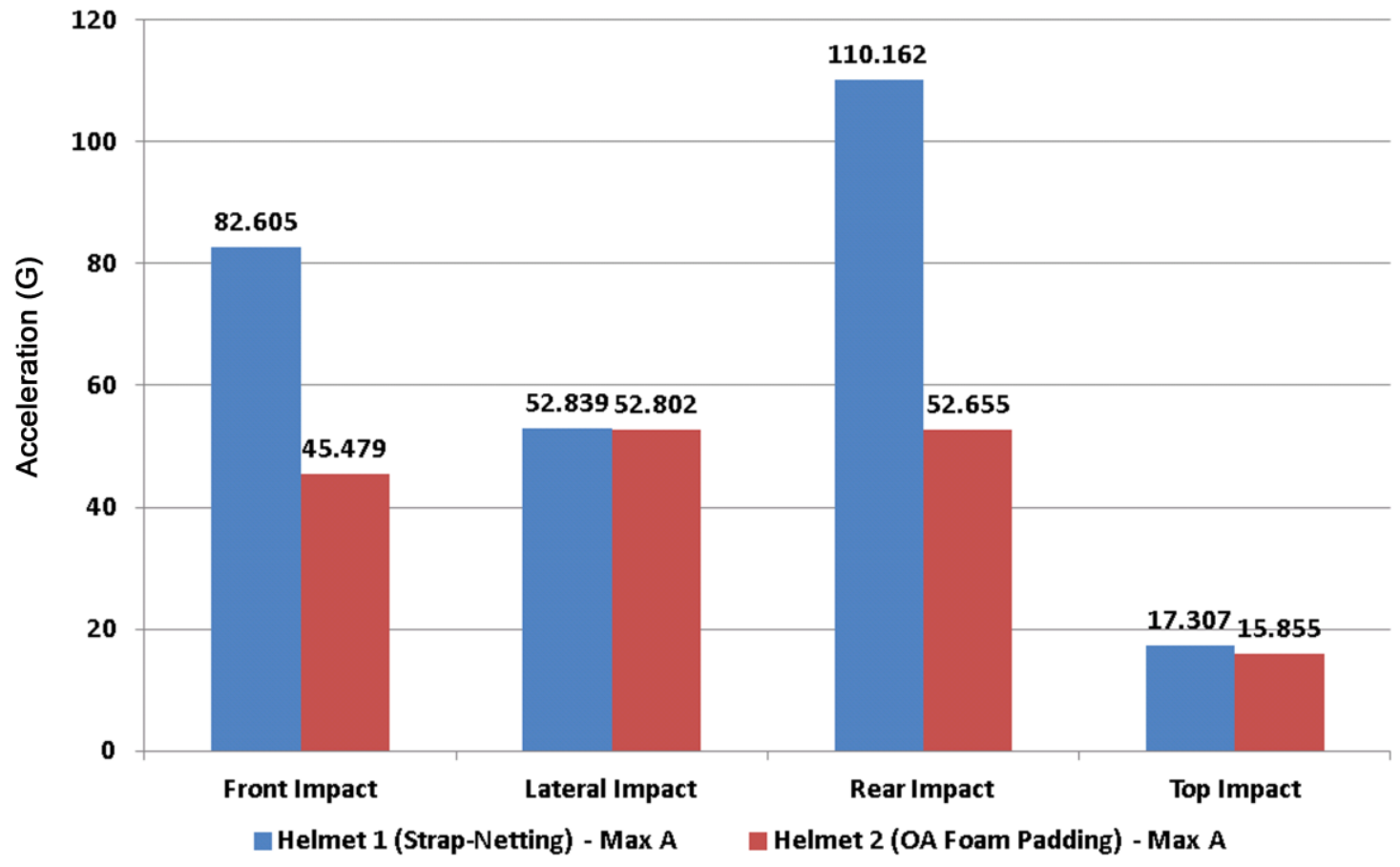

b

HIC Score for Various Impact Orientation and Helmet Configuration

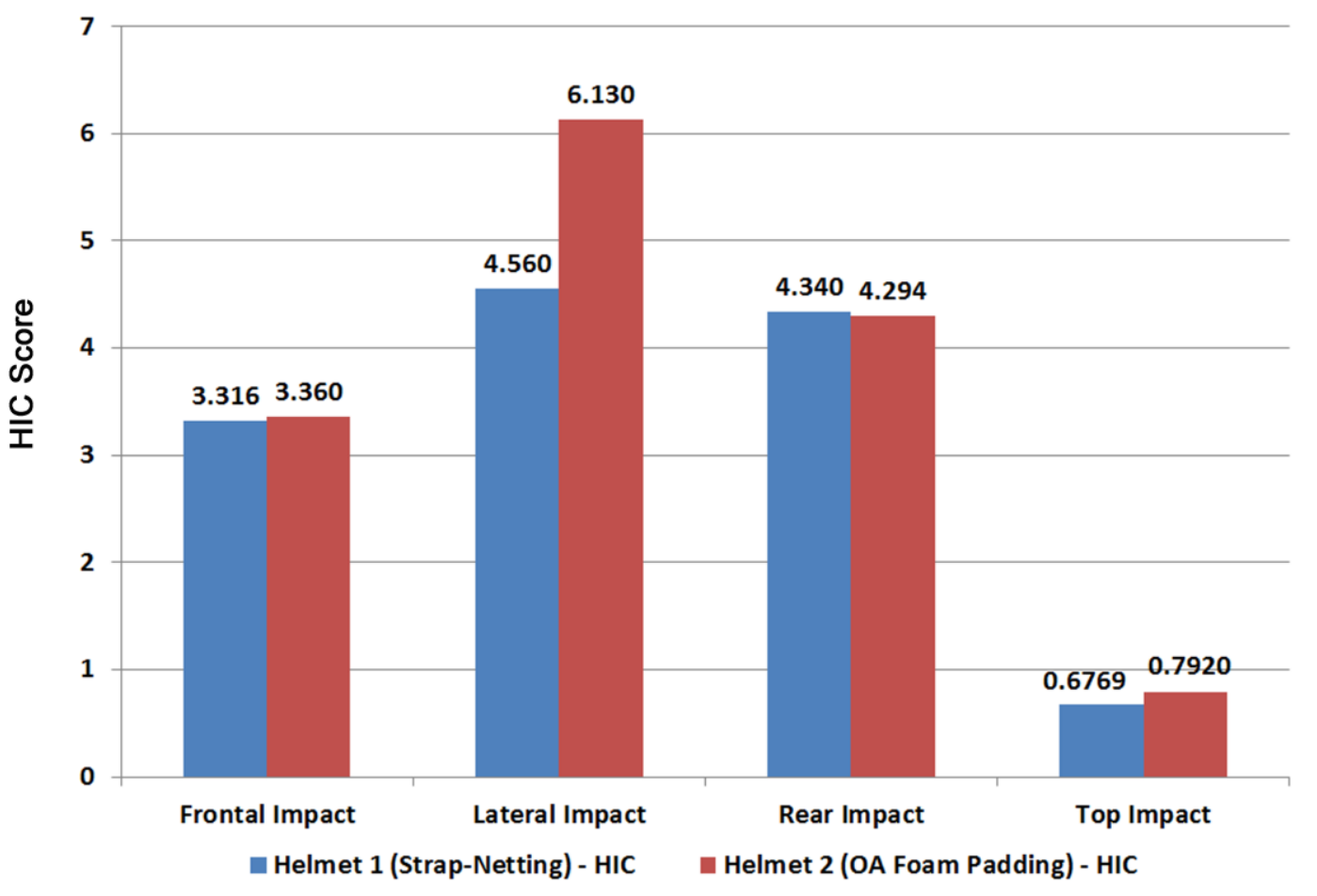


Appendix A: Impact sequence of the NIJ frontal impact for Helmet 1 (strap-netting).
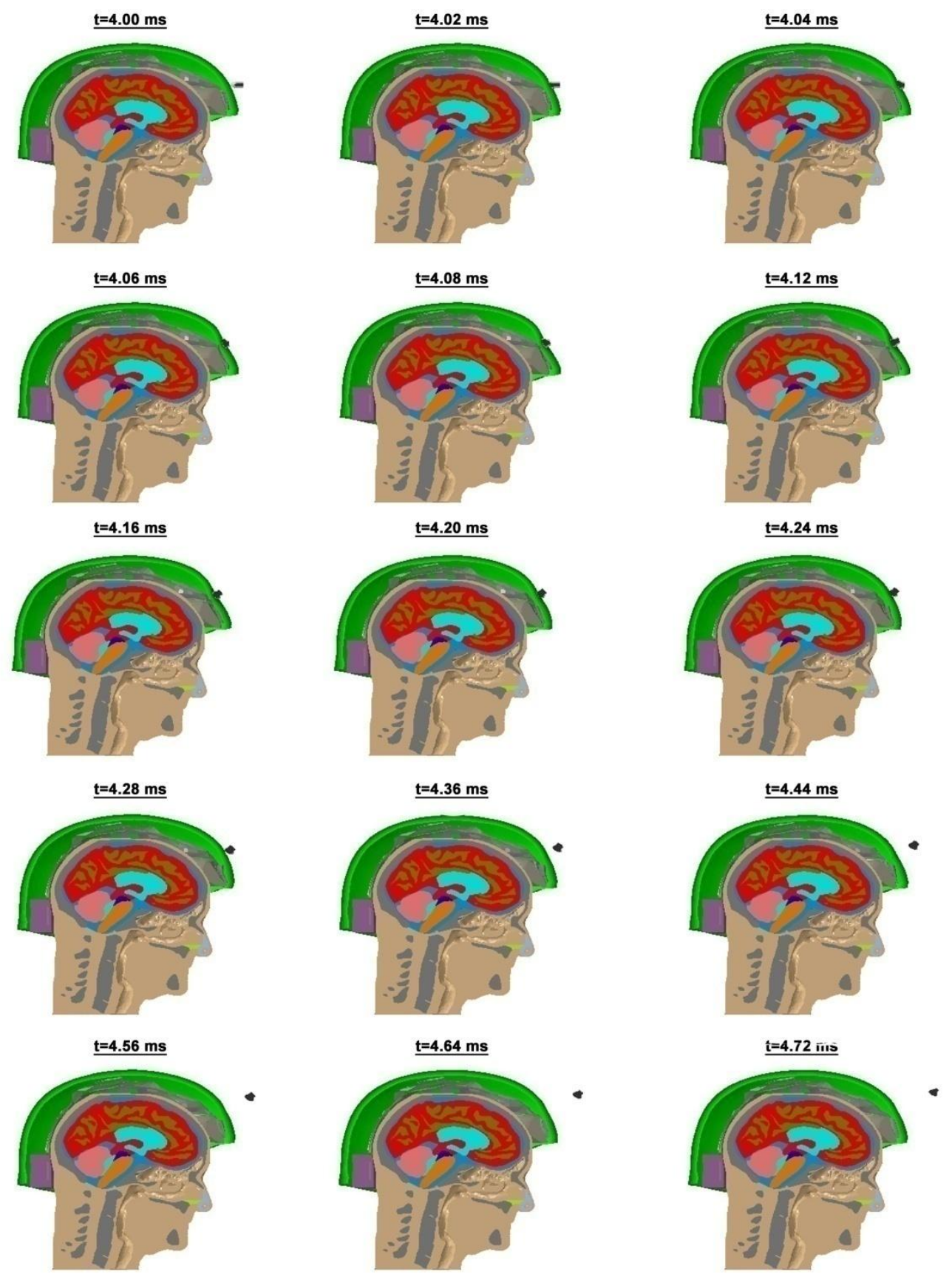
Appendix B: Impact sequence of the NIJ lateral impact for Helmet 1 (strap-netting).
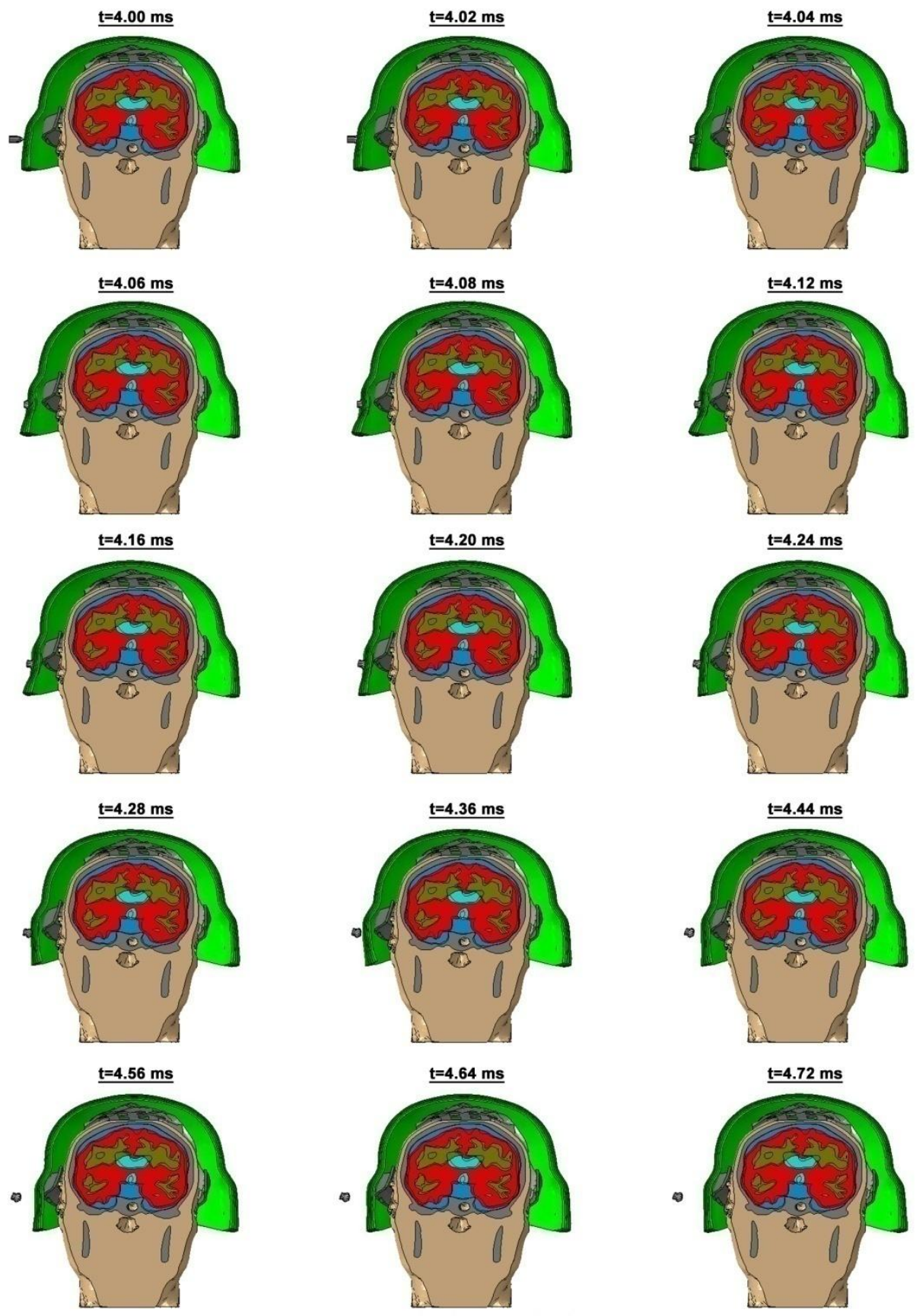
Appendix C: Impact sequence of the NIJ rear impact for Helmet 1 (strap-netting).
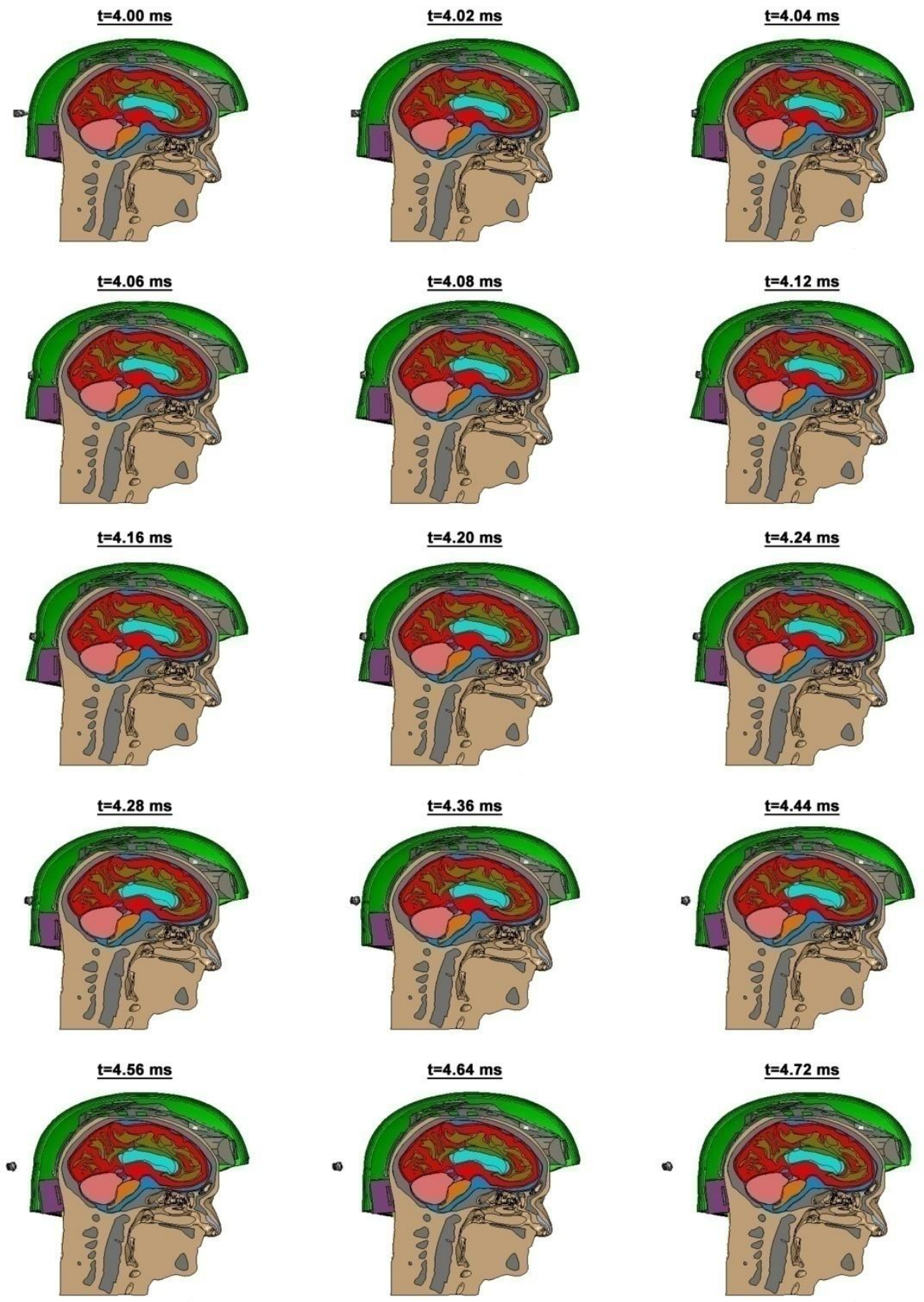
Appendix D: Impact sequence of the NIJ top impact for Helmet 1 (strap-netting).
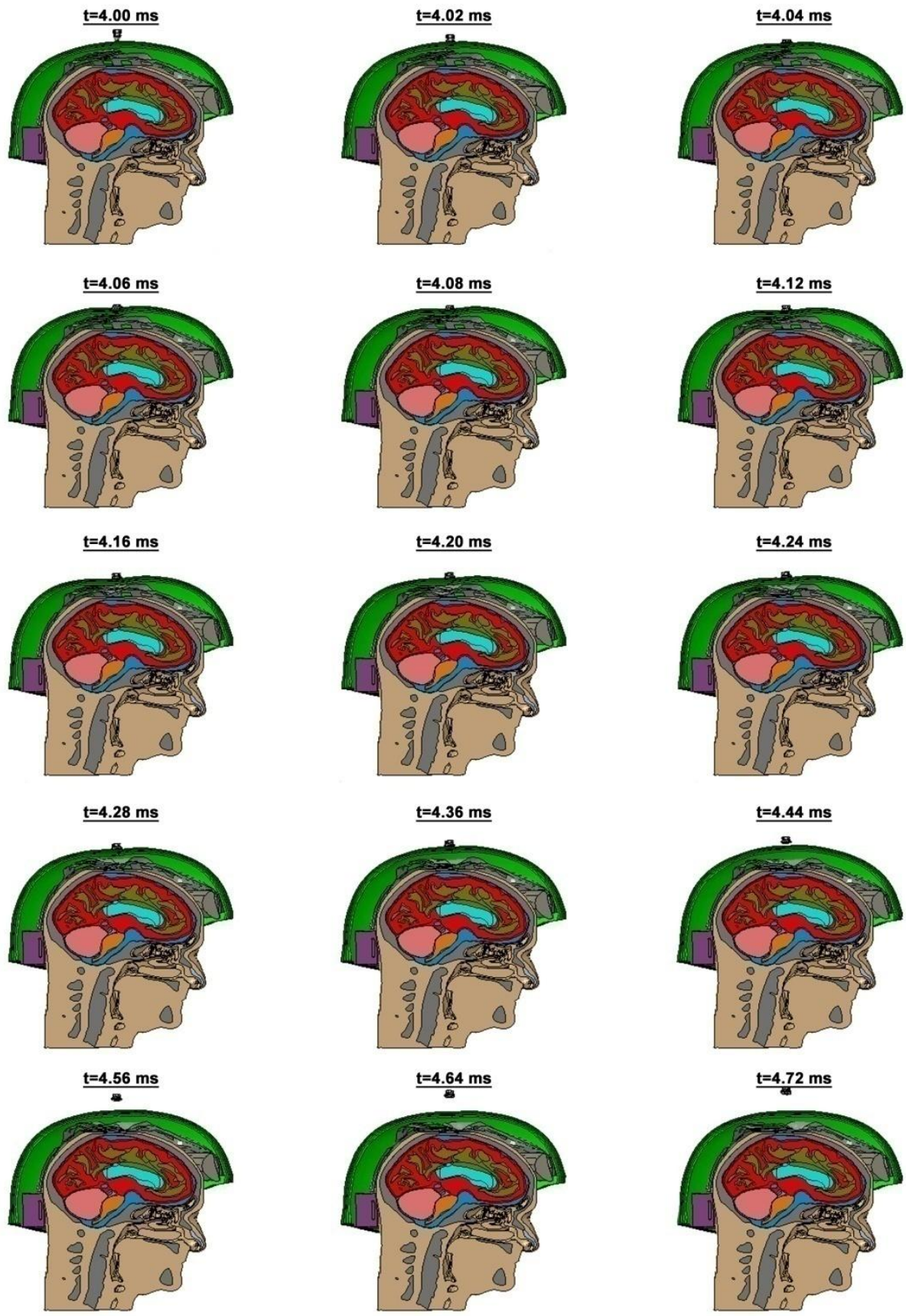
Appendix E: Impact sequence of the NIJ frontal impact for Helmet 2 (OA foam padding).
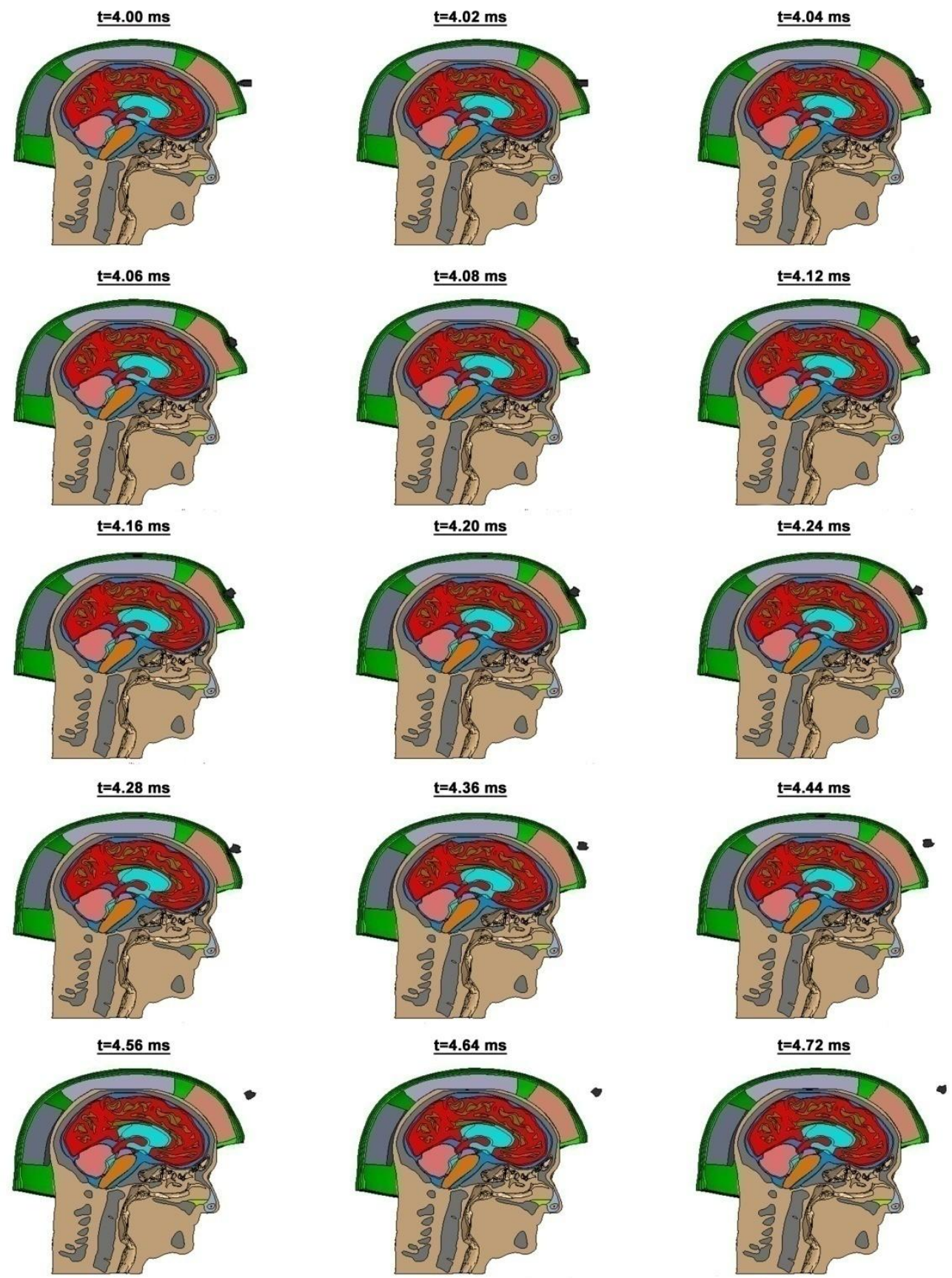
Appendix F: Impact sequence of the NIJ lateral impact for Helmet 2 (OA foam padding).
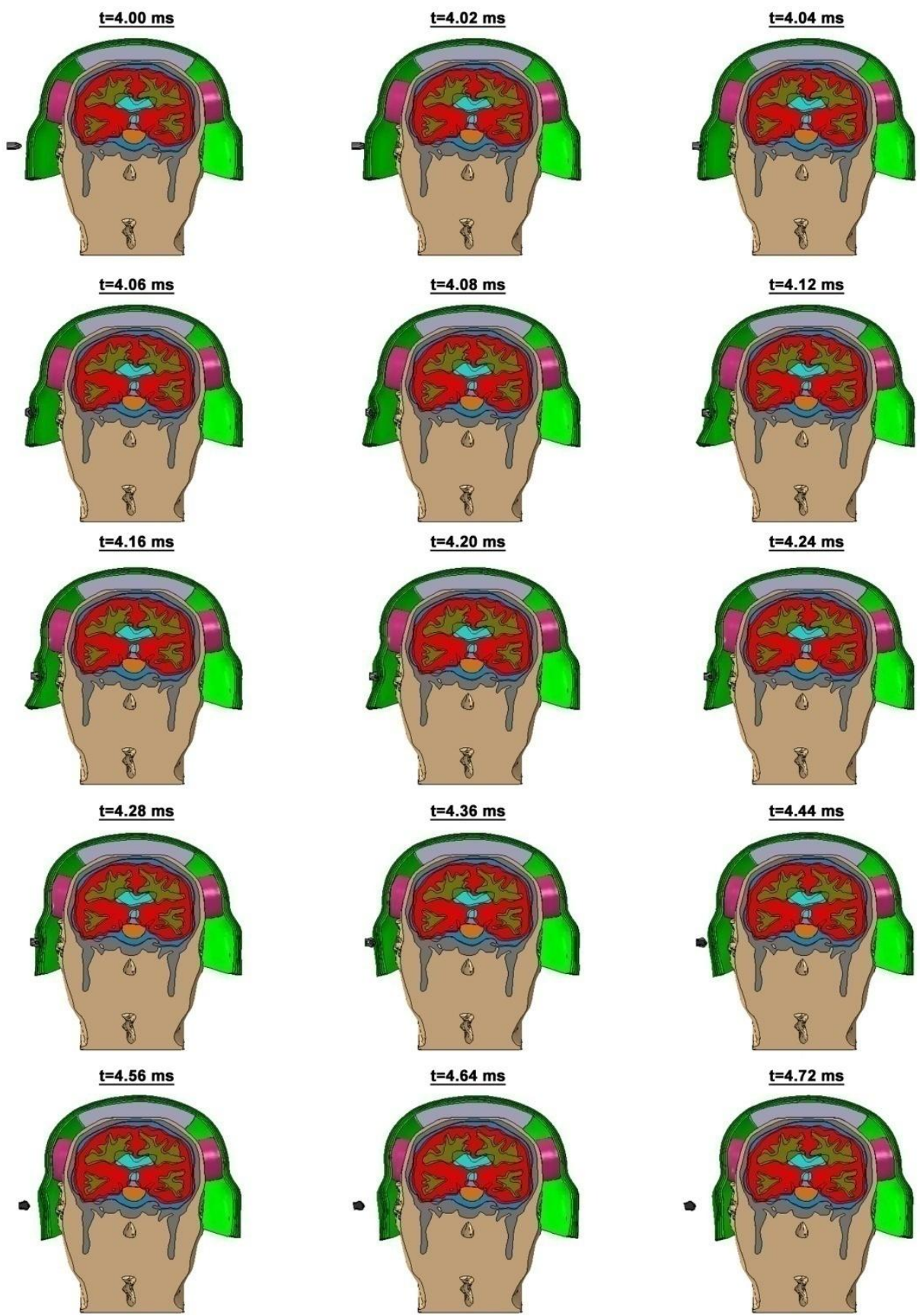
Appendix G: Impact sequence of the NIJ rear impact for Helmet 2 (OA foam padding).
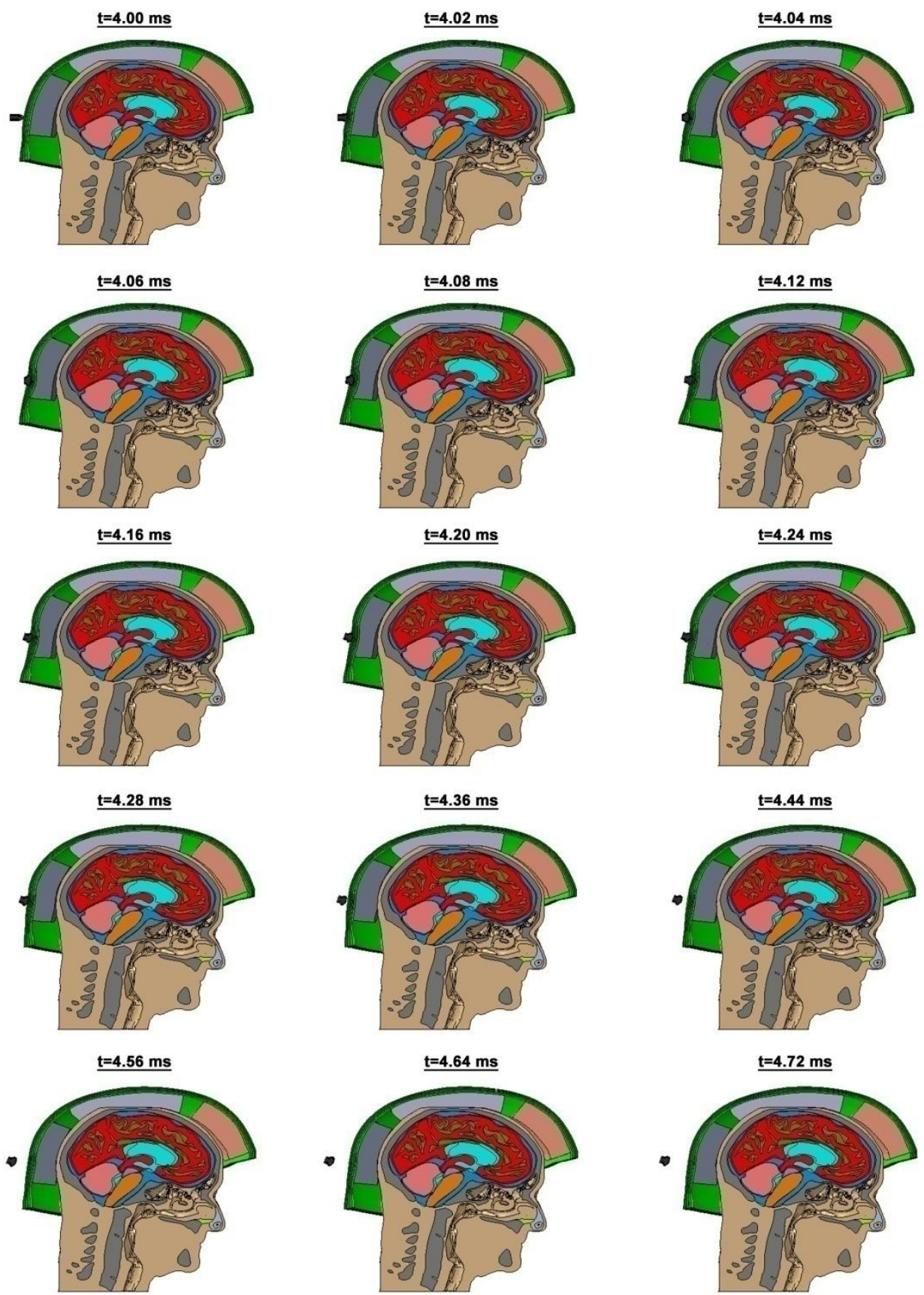
Appendix H: Impact sequence of the NIJ top impact for Helmet 2 (OA foam padding).
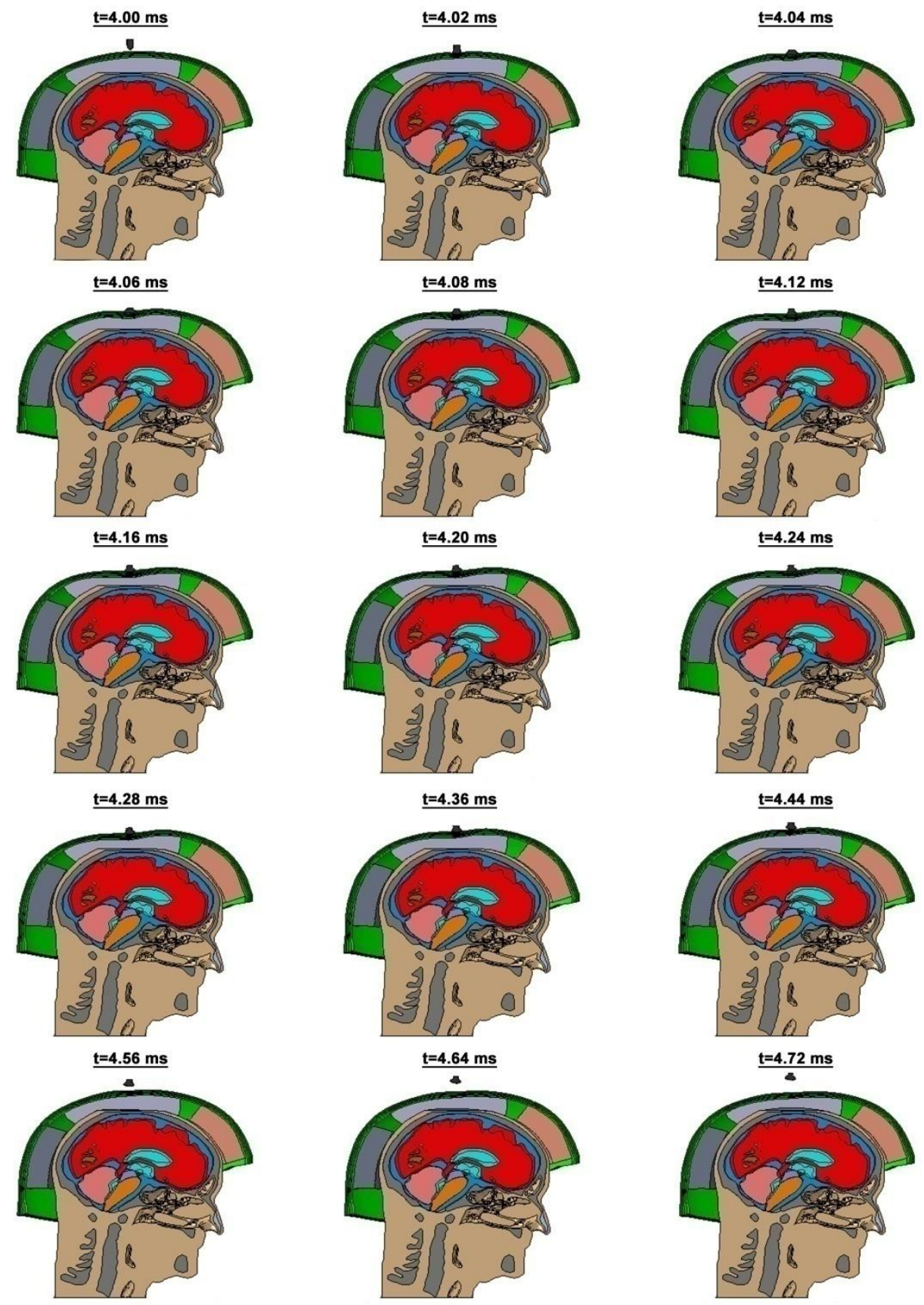


\section{University Library}

\section{- M M N E R VA A gateway to Melbourne's research publications}

Minerva Access is the Institutional Repository of The University of Melbourne

Author/s:

Tse, KM;Tan, LB;Yang, B;Tan, VBC;Lee, HP

Title:

Effect of helmet liner systems and impact directions on severity of head injuries sustained in ballistic impacts: a finite element (FE) study

Date:

2017-04-01

\section{Citation:}

Tse, K. M., Tan, L. B., Yang, B., Tan, V. B. C. \& Lee, H. P. (2017). Effect of helmet liner systems and impact directions on severity of head injuries sustained in ballistic impacts: a finite element (FE) study. MEDICAL \& BIOLOGICAL ENGINEERING \& COMPUTING, 55 (4), pp.641-662. https://doi.org/10.1007/s11517-016-1536-3.

Persistent Link:

http://hdl.handle.net/11343/283115 